\title{
B Tumbiense africano y sus correlaciones mundiales
}

\author{
por O. F. A. MENGHÍN
}

\section{LA INVESTIGACIÓN DEL TUMBIENSE HASTA 1939}

En 1925 y 1926 publiqué dos artículos sobre la edad de la piedra en la región del Congo', con el propósito de clasificar, desde el punto de vista cronológico y el histórico-cultural, el material lítico del Africa central, poco conocido y escasamente tratado hasta entonces. Nuevos conjuntos de hallazgos, cuya publicación científica me fuera cometida, motivaron esos trabajos. Para ellos pude basarme en el estudio de materiales análogos en los Museos de Berlín, París, Roma y Londres, y en el conocimiento de la bibliografía más antigua referente a este problema. El examen de la edad de la piedra en el Congo ofreció en aquel entonces grandes dificultades, porque en todos los casos se trataba de colecciones efectuadas por aficionados, desprovistas de los necesarios datos estratigráficos. Los artefactos pudieron juzgarse sólo en base al aspecto tipológico. Mis antecesores - en su mayoría - no se habían exteriorizado sobre la cuestión cronológica. Stainier, al que debemos la más importante contribución sobre material lítico del Congo ${ }^{2}$ lo calificó de neolítico. Mi resultado fué algo distinto. Creí poder demostrar que, a pesar de la aparente unidad del cuadro tipológico; es posible reconocer al menos dos, tal vez tres etapas evolutivas. Escribí que surge la idea de que en el Congo se presente una fase más antigua,

1. Mrnohí, O.: Die Tumbakultur am unteren Kongo und der westafrikenische Kulturkeis; en "Anthropos", t. XX, Viena, 1925, P. 516; del mismo autor: Neue Steinzeitfunde aus dem Kongosteate und ibre Beziebangen zum exropäiscben Compignien, en "Anthropos", t. XXI, Viena, 1926, p. 833.

2. Stainikr, X.: L'âge de la pierre an Congo, en "Annales du Musée du Congo Belge", D. Sér. I, tomo I, 1, 1899. 
perteneciente al Paleolítico superior, en la cual prevalece el aspecto de una cultura, relativamente pura, de hachas de mano a menudo de perfil planoconvexo, aunque no falten puntas hoja de laurel, y una fase posterior de aspecto mesolítico o epipaleolítico, caracterizada por el aumento de armas puntiagudas y ciertos elementos debidos a influencias neolíticas. Como tercera fase podría traerse a cuenta una capa final fuertemente neolitizada. Consideré toda esta serie como el despliegue de una rama local de la cultura del hacha de mano del Paleolítico superior, procedente de su antecesor bien conocido del Paleolítico inferior, el Acheulense. Llamé a esta rama Tumbiense, por ser la estación de Tumba el yacimiento más rico que se conocía en aquel entonces. Mostré que conjuntos arqueológicos semejantes se presentan no sólo en el África central, desde la Guinea septentrional hasta la Somalia, sino también en Europa (el Campiñense), en Indochina (el Bacsoniense) y hasta en Australia. Combiné la cultura del hacha de mano del Paleolítico superior con la cultura "de dos clases matrimoniales" de Graebner, que pasaba en aquel entonces por la más antigua cultura matriarcal y plantadora; los elementos neolíticos que influyeron sobre el Tumbiense más tarde, particularmente el hacha cilindriforme (Walkenbeil, sazessage-sbaped axe), los vinculé con la cultura del arco de Melanesia, es decir, con los plantadores matriarcales más avanzados en la terminología de los etnólogos.

Mis estudios fueron el primer ensayo más detallado de una asociación comparativa de datos arqueológicos y etnológicos referentes al Paleolítico, y depararon tal vez una sorpresa para muchos especialistas. No obstantr, mis ideas hallaron buena acogida entre los prehistoriadores, particularmente en Francia ${ }^{3}$, donde hubo para esos problemas más interés y comprensión que en Alemania. El término Tumbiense fué aceptado. Luego, en mi Weltgeschicbte der Steinzeit, Viena, 1931, pp. 41, 81, 221, articulé mi teoría en un sistema general y la profundicé mediante los nuevos descubrimientos de culturas pertenecientes en Asia sudoriental por Mansuy, Mlle. Colani, Stein-Callenfels y otros". Consideré ya entonces (p. 258) si el Tumbiense del Miolítico ( $=$ Paleolítico superior) pudo haber tomado origen de raíces indígenas africanas, siendo este continente un centro de la cultura del hacha de mano en el Protolítico ( $=$ Paleolítico inferior). Sin embargo, el estado de las investigaciones de aquella época no me permitió una visión clara de los hechos. La combinación del material arqueo-

3. Luquet, A. H.: en "L'Anthropologie", t. XXXVI, 1936, p. 575; t. XXXVII, 1937, p. 539. - Brevil, H.: L'Afrique prébistorique, en L' Afrique, "Cahiers d'Art", París, 1931. - HarRison, H. S.: en "Journ. R. Anthrop. Inst.", t. LXI, 1932, p. 434.

4. Me ocupe de estos hallazgos en un trabajo especial: Zur Steinzeit Ostasiens, ea "Festschrift f. P. W. Schmidt", Viena-Mödling, 1928. 
lógico y el etnológico, en cambio, me indujo a insistir con decisión en mis pensamientos acerca de la coherencia entre la cultura del hacha de mano miolítica y la más antigua cultura plantadota y matriarcal. También ya incluí en mis consideraciones (p. 225 y sig.) ciertos hallazgos americanos, y llamé la atención sobre la conveniencia de agrupar en este complejo cultural las muy discutidas hachas de mano de Trenton (New Jersey), como los objetos del arroyo Observación en la Patagonia. Expuse (p. 270) la presunción que la cultura del hacha de mano se difundió a lo largo de la costa del Asia que da al Pacífico y alcanzó las Américas a través del Estrecho de Behring.

Mientras tanto, un joven investigador belga había comenzado el estudio de la edad de la piedra en el Congo. Víctima de un desastre ${ }^{5}$, no pudo elaborar en su totalidad los resultados de sus esfuerzos, de manera que poseemos solamente unos artículos de su pluma ${ }^{6}$. Bequaert, después de la muerte de Colette, se hizo cargo de la publicación del material más significativo? ${ }^{7}$. Colette había tenido la suerte de descubrir un importante yacimiento cerca de Kalina, sobre la ribera izquierda del Congo, entre Kinshasa y Léopoldville. En este sitio se presentan cinco capas, de las cuales, sin embargo, sólo tres quedaron bien definidas. Tampoco pudieron aclararse perfectamente las relaciones de las cinco industrias observadas con respecto a los estratos geológicos. Colette en 1927 clasificó la más antigua de las culturas identificables, como Prechelense; en 1929 dividió el complejo paleolítico de Kalina en dos períodos: el Kaliniense y el Djokociense; en 1931 distinguió dos etapas en el Kaliniense, la más antigua de las cuales, sin embargo, según su descripción, no coincide por completo con su Prechelense de 1927. En el año 1933 creó para ciertos elementos del nivel superior de Kalina el término Leopoldiense, fase neolítica; propuso - por fin - tres etapas del Kaliniense e intercaló entre el Djokociense y el Leopoldiense otra fase neolítica, el Ndoliense. Añadió que el Djokociense y el Ndoliense pudieron ser contemporáneos al uso del hierro, idea extremadamente aventurada. Bequaert acentúa que entre los hallazgos de Kalina hay un solo objeto que corresponde a una auténtica hacha de mano del Paleolítico antiguo,

5. Necrologio de R. L. Doize, en "L'Anthropologie", t. XLVII, 1937, p. 185.

6. Colertr, J. R. F.: Trouvailles paléolitbiques en Congo Belge, en "XIV Congr. intern. d'anthr. et arch. préh., Amsterdam, 1927", Amsterdam, 1929; del mismo autor: Le prébistorique dans le Bas-Congo, en "Bull. Soc. R. Belge d'Anthr. et Préh.", t. XLIV, 1929; del mismo autor: Indisstrie paliolitbique du Congo belge, en "XV Congr. intern. d'anthr. et arch. préh.", París, 19j1; del mismo autor: Le nélitbique vélien, en "Bull. Soc. R. d'Anthr. et Préh.", t. XLVIII, 1933. del mismo autor: Complexes et convergences en Prebistoire, en "Bull. Soc. R. belge d'anthrop. et de préh.", t. L, 1935 .

7. Bequarrt, M.: Les fouilles de Jean Colette à Kalina, en "Annales du Musée du Congo Belge", D. Sér. I, t. 2, 1938. 
siendo confeccionada de pedernal y patinada, mientras que todas las demás son de grès (arenisca silicaria). Aquella hacha de mano debería ser considerada como intruso secundario, pero puede tomarse de todos modos como prueba de la existencia de un Paleolítico inferior en la región del Congo.

Al mismo tiempo que los trabajos de Colette, y en los años siguientes, hasta 1939, apareció un considerable número de monografias que se ocupaban, en parte de la geología, en parte de la arqueología de los hallazgos líticos del Congo y de los países colindantes ${ }^{8}$. La más importante de ellas es el artículo de Delcroix y Vaufrey, basado en excavaciones y recolecciones de R. Delcroix y M. Waterlot en la Guinea francesa, y culminando en explicaciones generales sobre el Tumbiense, por Vaufrey. El distinguido investigador francés cita en su exposición muchas nuevas monografias sobre el Tumbiense a partir de mis estudios, y además algunas anteriores, que yo había omitido. Con más detención examina los tratados de O’Brien, Colette y Droux y Bourgeaud. O'Brien halló en el valle del Kangera, el más importante río tributario del lago Victoria (Uganda), varias industrias líticas, que distribuyó a través de tres períodos: Tumbiense antiguo, medio y tardío, dando el nuevo nombre Prototumbiense al Sangoense evolucionado de Wayland', industria del tipo levalloisiense-musteriense con grandes

8. Schoutrdan, H.: Pientes taillées de l'Uéle, en "Bull. Cercle Zool. Congol.", 1927. Lompard, J.: Note préliminaire sur la géologie de l" Afrique équatorial frongsise, en "C. R. sem. soc. geol. de France", fasc. X, 1928. - BABET, V.: Etude géologique de la zone due cbemin de for CongoOctan, París, 1929. - De Mathelin Dr Papigni, H. : Les instruments de pierres de l' Afrique centrale et orientale, en "XV Congr. intern. d'Anthr. et Arch. préh." (París), 1931. - Lombard, J.: Mostriaux príbistorigues du Congo frenfais, en "Bull. soc. d. Africanistes, 1931.- Grazaon, ,P.: Industrie prebistorique delle serrazze del Congo, presso Leopoldville, en "Arch. per l'antropologia e la etnologia", t. LXII, 1933. - ConkTre, J. R. F.: Le néolitbique úlien, en "Ball. Soc. R. belge d'anthrop. et de préh.", t. XLVIII, 1933. - K prébistoriques au Congo, en "Journ. Soc. des Africanistes", t. IV, 1934. - SANTos Jonvon J. R. Dos: Rui de Serpa Pinto e a arqueologia de Angole, en "Actos do I Congresso nac. de antropologia colonial" , Porto, 1934. - W en "L'Anthropologie", t. XLV, 1935. - Leacery, L. S. B.: Stone Age Africa, Oxford, 1936. BabBt, V.: Note préliminaire sur un atelier de pierres taillées a Brozzooille (A. E. F.), en "Bull. soc. préh. franc." , 1936. - Droux, G. eт Brrgraud, G.: Noupeaux ateliers prébistoriques à Brazzaville, en "Bull. soc. recherches congol.", t. XXIV, Brazzaville, 1937.-O'Brme, T. P.: La Prébistoire dans Ougande, en "Bull. Soc. préh. franc.", 1937; del mismo autor: Prebistory of tbe Uganda Protectorate, Cambridge, 1937. - AvgrLrotr, H.: Station prébistorique, pieme d cupules et instrements toillke découverts au Congo belge par M. P. Ouvrard, en "Bull. Soc. R. Belge d'anthrop. et de préh.", t. LII, 1937. - Brquaknt, H. M.: Bijlen uit Neder-Congo, bijlen uit West-Ubange en bijlen uit Uele, en "Bull. de Séances, Inst. R. Belge", t. VIII, 1937. - Vayson de PradennNe: La Prébistoire,

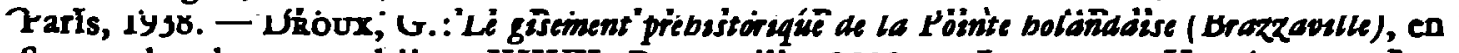
Soc. recherches congol.", t. XXVII, Brazzaville, 1939: - LaGotria, H.: $A$ propos $d$ une in trie litbique primitive du Conge fronģais, en "Mélanges Bégouen", Toulouse, 1939. - Pourna E.: Descripsion de pierres taillées provenant de la région dx Kassai, en "Bull. d. Séances de l'Inst royal col. belge", t. VI, 1935.

9. WaYLAND, E. J. aND Smitr, R. A.: Stome Implements from Uganda, en “Oceasional pers of the Geol. Survey of Uganda", Nr. 1, Entebbe, 1923; del mismo autor: Prebisteric mains and Stone-Age Cbronology, en "Ann. Rep. of the Geol. Survey Dep, 1927", Entebbe, 19 del miomo autor: African Pluvial Periods and Prebistoric Man, en "Man", t. XXIX, 1929, p. 

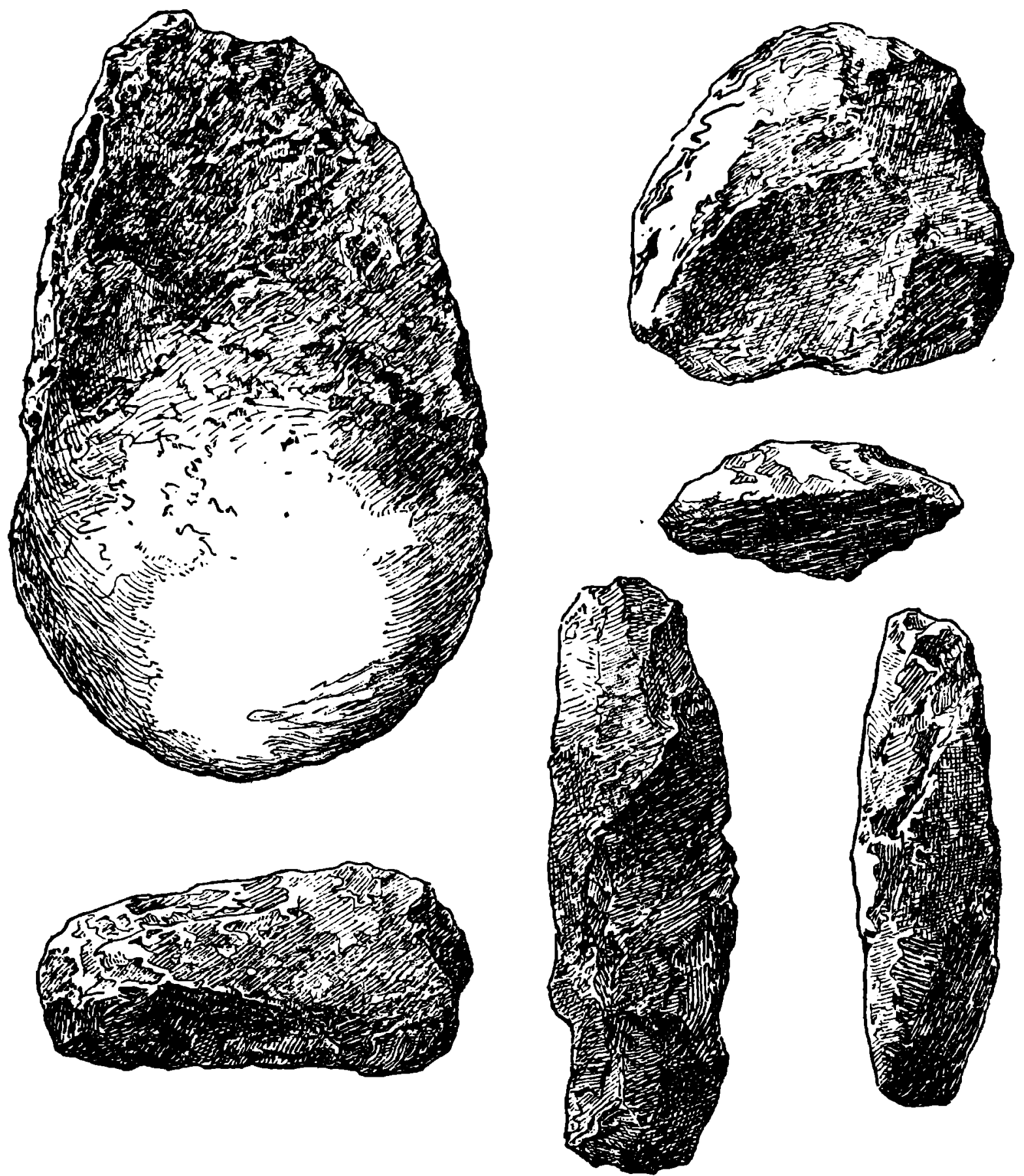

Fio. 1. - Tipos del Para-Tumbiense de Bomako (Sudán francés), según Vaufrey. Las piezas son todas aproximadam. el doble de la imagen, menos 12 superior derecha, que es 3/1.

hachas de mano de derivación acheulense. Según O’Brien, Uganda proporciona la prueba de que el Tumbiense tiene su origen en el Acheulense, ya que tipos tumbienses se encuentran juntos con acheulenses. Vaufrey pone en duda la edad de los hallazgos respectivos, pero injustamente, como fué averiguado a raíz de las investigaciones posteriores. También la aplicación del término Prototumbiense a esta industria evocó controversias; hablaremos más adelante del resultado de las mismas.

En lo que se refiere a las investigaciones de Colette, Vaufrey mantiene 
la opinión que ya había expuesto en el año $1934^{10}$, según la cual los descubrimientos del explorador belga pertenecen al Tumbiense clásico, es decir, a una facies lítica muy tardía neolitizada. Vaufrey se ocupó nuevamente de esta cuestión, reseñando los trabajos de Bequaert, Droux y Bergeaud". y volvió a insistir - también en esta oportunidad- en su juicio, exceptuando únicamente la mencionada hacha de mano de claro aspecto protolítico. Djokociense como Ndoliense le parecen nada más que expressions partielles del Tumbiense, "le premier comportant notammont des feuilles bifaces grandes et petites, des flècbes pédonculées et méme des flicbes a tranchant transversal, ainsi que des lamelles d dos rabattu et des grattoirs, le second, des becbes d biseaw et des trancbants, des flicbes a tranchant transversal et des pointes foliacies".

Droux y Bergeaud se refieren a hallazgos tumbienses en arenas y gravas aluviales de la terraza de 7 metros de altitud de M'Pila al Noreste, y de M'Piaka al Oeste de Brazzaville, cerca del Stanley Pool. En M'Pila contiene una capa arqueológica de 3,50 metros de profundidad artefactos tumbienses grandes y pequeños y puntas de flecha de filo transversal (trapecios). Faltan tiestos de alfarería, que existen en el yacimiento de Kinshasa, situado en una cercana terraza del mismo nivel. Los excavadores atribuyen gran importancia a este hecho, mientras que Vaufrey lo considera como fortuito. En M'Piaka aparecieron bajo el estrato tumbiense, en una capa de grava, toscas piedras rodadas con escasos retoques, residuos de una industria mucho más antigua, según el parecer de los autores, opinión que 2 Vaufrey parece posible, pero no comprobada. Tratándose, en efecto, de un Acheulense, Vaufrey no deduciría de ello una conexión genética coṇ el Tumbiense, sino sólo una semejanza en base de convergencia, de igual manera que en el caso de las finas hojas de trabajo bifacial que figuran en el Acheulense, Solutrense y Neolítico europeos.

La teoría propia de Vaufrey sobre la cronología y genealogía del Tumbiense reconoce su aspecto mesolítico y la extraordinaria similitud del Tumbiense con el Campiñense epimiolítico de Europa, pero la fecha, a pesar de todo, en el verdadero Neolítico pleno; combina sus instrumentos pétreos de retoque bifacial con los de las industrias egipcias del Neolítico temprano (Merimdiense, Tasiense, Badariense) y los tipos sobre lascas, particularmente los trapecios, con el Neolítico norteafricano de tradición capsiense.

El concepto de Vaufrey fué, por lo tanto, muy distinto del mío. Yo creía poder reconocer un desarrollo del Tumbiense, que ya comienza en el Miolítico, y no excluí el origen local, es decir centroafricano, de esta

10. "L'Anthropologie", t. XIIV, 1934, p. 164.

11. "L'Anthropologic", t. L, 1940, p. 239. 
cultura, reconduciendo los elementos neolíticos a infiltraciones secundarias y tardías. Ignoraba la presencia de trapecios y otros tipos microlíticos norteafricanos en el conjunto del Tumbiense. Si hubiese conocido este hecho, lo hubiera explicado igualmente por influencias capsienses, pero no del Neolítico de tradición capsiense, sino del auténtico Capsiense del Miolítico final. Claro está que esta disparidad en los juicios sólo podía resolverse con argumentos estratigráficos. Aunque los trabajos aparecidos después de mis publicaciones ofrecieron cuantiosos indicios, por los cuales la existencia del Protolítico con hachas de mano en la cuenca del Congo y la derivación local de una cultura miolítica de semejante carácter resultaron cada vez más evidentes, pudo mantenerse sin embargo el escepticismo acerca de mis ideas, mientras las observaciones geológicas de los estratos respectivos no resultaren más exactas.

\section{LAS INVESTIGACIONES EN ÁFRICA CENTRAL DESPUÉS DE 1939}

Trabajos comenzados unos años antes de la segunda guerra mundial, y continuados durante la misma, han aclarado definitivamente los problemas fundamentales. Se trata, por un lado, de investigaciones efectuadas por el explorador belga Cabu en la región del Congo ${ }^{12}$ y por el otro de la

12. F. Casú estudió el Paleolítico del Congo en su tesis de doctorado y en un discurso pronunciado en el Congreso internacional de Antropología y Prehistoria de Bruselas en 1935. Pero sus investigaciones no fueron conocidas por un número mayor de interesados, antes de que el Abbé Breuil y van Rirt Lowr se ocuparon de ellas. Vea: Breuil, H.: Le Palíalitbique au Congo Belge d'apris les recbercbes du Doctor Cabu, y Les industries de la terrasse de 15 métres et d'un cbenal secondaire comble, Plaine de Piemont de Leopoidville, etc., en "Transactions of the R. Soc. of South Africa", t. XXX/2, Cape Town, 1944; y C. vaN Rier Lown: Notes on Dr. Francis Cabú Collection of Stone Implements from tbe Belgian Congo; ibidem. No dispongo de suficientes noticias respecto a las consideraciones referentes al Paleolítico centroafricano en los congresos de Nairobi 1947 y Bruselas 1948, pero sí de una amable carta de Abbé Breuil del 19 de diciembre de 1948, conteniendo un breve tratado sobre la sucesión de las culturas líticas del Congo. Cfr. Hautmann, F.: Das Paläalisbikum Zentralafrikes und seine Chronologie in Lichte neuer Forschungen, en "Bull. de la Soc. suisse d'Anthr. et d'Ethn.", t. XXIV-XXV, 1949. - Además, desde 1939 aparecieron muchos artículos sobre materiales pertenecientes al Paleolítico del Congo, a veces con importantes observaciones estratigráficas locales: Brquakat, M.: Hacbes de l'Oubangbi, en "Bull. Soc. R. belge d'anthrop. et de préh.", t. LV, 1940; del mismo autor: Presentation de pièces, Ibídem; del mismo autor: Jongere Steentijdperkkulturen in Belgiscb-Congo, en "Natuurwetenschappelijk Tijdschrift, t. XXIV, 1942; del mismo autor: Bijdrage tot de Studie van de Vórgescbiedenis in Ruonda-Urandi, Ibidern; del mismo autor: Deux pierres taillées de l'Angumu, en "Bull. d. Séances de l'Institut royal col. belge", t. XIV, 1943; del mismo autor: Instrument en pierre taillée du bassin de la Lukénie (Congo belge), Ibiden; del mismo autor: Twee Steenen Werktuigen wit bet Bekken van de Wenji, en "Natuurwetenschappelijk Tijdschrift", t. XXV, 1943; del mismo autor: Pierres saillées de Tsbungm-Kapumba; en "Bull. Soc. R. belge d'anthrop. et de préh.", t. LVI, 1945; del mismo autor: Contribusion a la connasissence des industries de la pierre taille dans le Nord-Est du bessin dx Congo, Ibidem. - Prerr, V. : Sur l dge de lo pierre dons l" Ituri, en "Technique et Colonie", 
la opinión que ya había expuesto en el año $1934^{10}$, según la cual los descubrimientos del explorador belga pertenecen al Tumbiense clásico, es decir, a una facies lítica muy tardía neolitizada. Vaufrey se ocupó nuevamente de esta cuestión, reseñando los trabajos de Bequaert, Droux y Bergeaud"1. y volvió a insistir - también en esta oportunidad - en su juicio, exceptuando únicamente la mencionada hacha de mano de claro aspecto protolítico. Djokociense como Ndoliense le parecen nada más que expressions partielles del Tumbiense, "le premier comportant notamment des feuilles bifaces grandes et petites, des flèches pédonculées et même des flèches à tranchant transversal, ainsi que des lamelles d dos rabattu et des grattoirs, le second, des baches a biseau et des tranchants, des flicbes à trancbant transversal et des pointes foliacées".

Droux y Bergeaud se refieren a hallazgos tumbienses en arenas y gravas aluviales de la terraza de 7 metros de altitud de M'Pila al Noreste, y de M'Piaka al Oeste de Brazzaville, cerca del Stanley Pool. En M'Pila contiene una capa arqueológica de 3,50 metros de profundidad artefactos tumbienses grandes y pequeños y puntas de flecha de filo transversal (trapecios). Faltan tiestos de alfarería, que existen en el yacimiento de Kinshasa, situado en una cercana terraza del mismo nivel. Los excavadores atribiyen gran importancia a este hecho, mientras que Vaufrey lo considera como fortuito. En M'Piaka aparecieron bajo el estrato tumbiense, en una capa de grava, toscas piedras rodadas con escasos retoques, residuos de una industria mucho más antigua, según el parecer de los autores, opinión que a Vaufrey parece posible, pero no comprobada. Tratándose, en efecto, de un Acheulense, Vaufrey no deduciría de ello una conexión genética con el Tumbiense, sino sólo una semejanza en base de convergencia, de igual manera que en el caso de las finas hojas de trabajo bifacial que figuran en el Acheulense, Solutrense y Neolítico europeos.

La teoría propia de Vaufrey sobre la cronología y genealogía del Tumbiense reconoce su aspecto mesolítico y la extraordinaria similitud del Tumbiense con el Campiñense epimiolítico de Europa, pero la fecha, a pesar de todo, en el verdadero Neolítico pleno; combina sus instrumentos pétreos de retoque bifacial con los de las industrias egipcias del Neolítico temprano (Merimdiense, Tasiense, Badariense) y los tipos sobre lascas, particularmente los trapecios, con el Neolítico norteafricano de tradición capsiense.

El concepto de Vaufrey fue, por lo tanto, muy distinto del mío. Yo creía poder reconocer un desarrollo del Tumbiense, que ya comienza en el Miolítico, y no excluí el origen local, es decir centroafricano, de esta

10. "L'Anthropologie", t. XLIV, 1934, p. 164.

11. "L'Anthropologie", t. L, 1940, p. 239. 
cultura, reconduciendo los elementos neolíticos a infiltraciones secundarias y tardías. Ignoraba la presencia de trapecios y otros tipos microlíticos norteafricanos en el conjunto del Tumbiense. Si hubiese conocido este hecho, lo hubiera explicado igualmente por influencias capsienses, pero no del Neolítico de tradición capsiense, sino del auténtico Capsiense del Miolítico final. Claro está que esta disparidad en los juicios sólo podía resolverse con argumentos estratigráficos. Aunque los trabajos aparecidos después de mis publicaciones ofrecieron cuantiosos indicios, por los cuales la existencia del Protolítico con hachas de mano en la cuenca del Congo y la derivación local de una cultura miolítica de semejante carácter resultaron cada vez más evidentes, pudo mantenerse sin embargo el escepticismo acerca de mis ideas, mientras las observaciones geológicas de los estratos respectivos no resultaren más exactas.

\section{LAS INVESTIGACIONES EN ÁFRICA CENTRAL DESPUÉS DE 1939}

Trabajos comenzados unos años antes de la segunda guerra mundial, y continuados durante la misma, han aclarado definitivamente los problemas fundamentales. Se trata, por un lado, de investigaciones efectuadas por el explorador belga Cabu en la región del Congo ${ }^{12}$ y por el otro de la

12. F. Camú estudió el Paleolítico del Congo en su tesis de doctorado y en un discurso pronunciado en el Congreso internacional de Antropología y Prehistoria de Bruselas en 1935. Pero sus investigaciones no fueron conocidas por un número mayor de interesados, antes de que el Anbé Breunc y van Ribt Lowe se ocuparon de ellas. Vea: Breuil, H.: Le Paléolitbique au Congo Belge d'apris les recbercbes du Doctor Cabí, y Les industries de la terrasse de 15 métres et d'un cbenal secondaire comble, Plaine de Piemons de Leopoldville, etc., en "Transactions of the R. Soc. of South Africa", t. XXX/2, Cape Town, 1944; y C. van Rut Lowz: Notes on Dr. Francis Cabú Collection of Stone Implements from tbe Belgian Congo; ibídem. No dispongo de suficientes noticias respecto 2 las consideraciones referentes al Paleolítico centroafricano en los congresos de Nairobi 1947 y Bruselas 1948, pero sí de una amable carta de Abbé Breuil del 19 de diciembre de 1948, conteniendo un breve tratado sobre 12 sucesión de las culturas líticas del Congo. Cfr. Hautmann, F.: Das Paläolitbikem Zentralafrikas und seine Cbronologie in Licbte neuer Forscbungen, en "Bull. de la Soc. suisse d'Anthr. et d'Ethn.", t. XXIV-XXV, 1949. - Además, desde 1939 aparecieron muchos artículos sobre materiales pertenecientes al Paleolítico del Congo, a veces con importantes observaciones estratigráficas locales: Brquarrt, M.: Hacbes de lOubangbi, en "Bull. Soc. R. belge d'2nthrop. et de préh.", t. LV, 1940; del mismo autor: Présentation de pieces, Ibídem; del mismo autor: Jongere Steentijdperkkulturen in Belgiscb-Congo, en "Natuurwetenschappelijk Tijdschrift, t. XXIV, 1942; del mismo autor: Bijdrage tot de Studie van de Vórgescbiedenis ins Rwonde-Urandi, Ibidem; del mismo zutor: Deux pierres taillées de l'Angumu, en "Bull. d. Séances de l'Institut royal col. belge", t. XIV, 1943; del mismo autor: Instrument as pierre taillée du bassin de la Lukinil (Congo belge), Ibidem; del mismo autor: Twee Steenen Werktuigen wit bet Bekken oen de Wenji, en "Natuurwetenschappelijk Tijdschrift", $t$. XXV, 1943; del mismo autor: Pierres caillés de Tsbungw-Kapumba; en "Bull. Soc. R. belge d'anthrop. et de préh.", t. LVI, 1945; del mismo autor: Combribution a la connaissance des industries de le pierre taille dons le Nord-Est du bassin du Congo, Ibidem. - Prert, V.: Sur l dge de la pierre dans l Ituri, en "Technique et Colonie", 
nueva publicación sobre el Paleolítico del África oriental por Leakey and Owen' ${ }^{13}$. Además merecen mención varios artículos sobre el Paleolítico de Angola y Moçambique ${ }^{14}$.

El examen del material acarreado por Cabu y sus propios estudios en el terreno, realizados en el año 1948, permitieron a Breuil la formación de una clara cronología del Paleolítico en la región del Congo. El orden de las etapas culturales es el siguiente:

1. Cultura de guijarros (pebble culture) y algo de Protoabbevilliense rodado (terraza de $20 \mathrm{~m}$.).

2. Abbevilliense desarrollado, algo rodado (terraza de $10 \mathrm{~m}$.).

3. Acheulense antiguo y medio rodados (gravas en el fondo de los valles).

4. Acheulense final, rodado (sobre la grava de la terraza de $10 \mathrm{~m}$., en una capa de limo, claramente in situ).

5. Kaliniense (en la base de las arenas de Kalahari, rellenando los valles hasta un espesor de $90 \mathrm{~m}$.), divisible en dos facies: a) instrumentos (bifaces) muy toscos, que recuerdan por su técnica un Abbevilliense primitivo, en parte de tamaño no usual y manejables sólo con ambas manos, evidentemente usados para excavar materias primas; $b$ ) tipos más finos, particularmente núcleos y lascas levalloisienses, a veces artefactos de mejor calidad, con puntas hoja de laurel de talla bifacial, prototipos de los elegantes productos de los períodos posteriores.

I, 1945. - Mortrumans, G.: Prébistoire et quaternaire du Sud du Bassin du Congo, en "Session extraord. des Soc. Belges de Gtologie, 1946. - Barquarrt, M.: Contribution d l' étude de le prébisterie de l'Oubengbi, en "Bull. Soc. R. belge d'anthrop. et de préh.", t. LVII, 1946; del mismo autor: Bijdrage tot de kennis van bet Steentijdperk in bet land der Basbilange, en "Annales du Muste d o Congo Belge", D, Str. I, t. I, 5; 1947; del mismo autor: Tweede Bijdrage tot de Studie van de $V$ b́rgescbiedenis in Reanda-Urundi, en "Natuurwetenschappelijk Tijdschrift", t. XXX, 1948; Hrinzzlin DB BraucourT, J. DE: Industrie litbique des graviers aurifizes de la Lodjo (Ituri, Congo Belge), description de la collection V. Piret, en "Bull. Mus. R. d'Hist. nat. de Belgique", $t$. XXIV, 1948. - Fincd, H.: Tbe University of California African Expedition II. Sudan and Kenya, en "American Anthrop.", t. LI, 1949, p. 72.

13. LaAkeY, L. S. B. AND OwEN, W. E.: A Contribution to tbe Study of tbe Tumbien Culture in East Africe, en "Occ2s. Paper, Coryndon Mem. Mus.", Nr. 1, Nairobi, Kenya, 1945.

14. VAN RiBt LowB, C. AND BREUII, H.: First impressions of an Arcbacological Tour of tbo Sousbern Extremity of the Colony of Mogambique, en "Comissao dos Monumentos e Reliquias Hiscoricas de Moçambique", Lourenço Marques, 1944. - Janmart, J.: Les statjons pallolitbiques de l'Angola du Nord-Est, y Analyse glologique, climatalogique of probistorique d'un sondage fait on berdure de la rividre Luembe (Angole du Nord-est), en "Publicaçōes culturais da Companhia de diamantes de Angola", No 1, Lisbor e Dundo, Lunda, Angola, 1946; del mismo autor: Lo station pubisserique de Condala (district do lo Lunda, Angola du Nord-Est); del mistno autor: Sur la pasition

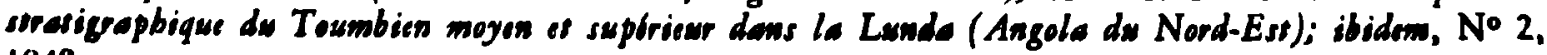
1948. 
Estas cinco etapas forman el Paleolítico inferior o Protolítico del Congo. El Paleolítico superior o Miolítico comprende igualmente varias etapas culturales.

1. Djokociense, cultura avanzada con puñales agudos, buenas puntas hoja de laurel, en parte largas y de bastante espesor, picos (picks) de mano, cinceles, etc., todos tallados en ambas caras, y a menudo con aplicación del retoque mediante presión. La derivación de esta cultura del Kaliniense es manifiesta.

2. Lupembiense, desarrollo ulterior del Djokociense, distinguido por la reaparición de la técnica levalloisiense (núcleos y láminas), artefactos sobre lascas (entre ellos mediaslunas, raspadores, raederas), además puntas en forma de hojas, a menudo tan reducidas y finas, que pudieron servir para armar dardos y flechas, a veces provistas de un pedicelo, cinceles fusiformes, picos de mano de tamaño regular, etc.

3. Tshitoliense, industria de época de transición, con tendencia microlítica, hojas de laurel, a menudo no más grandes que puntas de flecha, puntas de flecha con pedicelo y alas, mediaslunas, trapecios y diferentes artefactos de lascas. Falta todavía la cerámica, que sólo aparece en el período posterior, junto con el aumento de los microlitos y tipos neolíticos de la punta de flecha, pero por lo visto sin hachas. alisadas o pulimentadas y rompecabezas, que son aún más recientes.

Este breve resumen de los resultados obtenidos por las últimas exploraciones de Breuil nos suministra valiosos conocimientos. No cabe duda de que en la cuenca del Congo se trata de un desarrollo continuo a partir del comienzo del Paleolítico, por cierto con intromisiones extranjeras, ante todo levalloisienses y capsienses, pero en lo esencial determinado por la cultura del hacha de mano. Esta se transformó en la región del Congo, poco a poco, de manera que se la debe calificar de miolítica a partir del Djokociense. Se confirma de tal modo mi teoría, expuesta en mi Weltgescbicbte der Steinzeit, pp. 210, 257, que hemos de colocar al lado de las culturas de lascas miolíticas otra serie evolutiva, las culturas del hacha de mano (o de nódulo) miolíticas, ambos grupos procedentes de los complejos correspondientes del Protolítico. Ciertamente me inclinaba en aquel entonces 2 creer que este movimiento cultural se hubiera efectuado únicamente en las Indias, y que afectó al Africa sólo más tarde. Pero ya el progreso de las investigaciones entre 1931 y 1939 (especialmente el citado trabajo de Graziosi), me había convencido de que el papel del África central en este proceso fué mucho menos subordinado. Presumo actualmente que no sólo 
en el Protolítico - lo que es reconocido por la mayoría de los especialistas ${ }^{15}$ - sino también en el Miolítico, toda la zona tropical formó una relativa unidad, un círculo de vida cerrado, con relaciones bastante vivaces, y con tantos rasgos comunes, que bien puede hablarse de un círculo cultural. Las condiciones raciales refuerzan esta teoría, existiendo en ambos extremos del cíngulo tórrido una raza negroide, los negros de África y los melanesios de Oceanía, los últimos originalmente más. extendidos en el Asia meridional. No son idénticos, como no es idéntico enteramente su acervo arqueológico-cultural. Pero hay hechos que indican antiguas relaciones, cuyas peculiaridades por cierto tienen todavía que estudiarse más detenidamente.

Los nuevos conocimientos arrojan luz también sobre las relaciones del Congo con el resto de África. Solamente quisiera considerar aquí las conexiones con el Norte. Hoy ya no es posible ver el origen del Miolítico del Congo con la visual de Vaufrey. El trabajo bifacial no es ya el don de próximas culturas neolíticas, sino una herencia protolítica, como ya lo he conjeturado desde un principio. Las tendencias microlíticas se originan indudablemente en el Capsiense norteafricano, pero el hecho de comenzar a aparecer durante el Lupembiense no habla en favor de las fechas recientes que Vaufrey les atribuye. Por cierto, no es posible hoy día coordinar con absoluta seguridad las fases culturales y geológicas del África central y septentrional; pero las observaciones estratigráficas de Breuil, según las cuales el Lupembiense está situado en una terraza baja, que no representa la última de estos sistemas fluviales, comprueba una cierta antigüedad de su contenido arqueológico. El mismo Breuil correlaciona - sin duda correctamente- con el Lupembiense, el Middle Stone Age del África mèridional y una parte del Miolítico tardío de Europa (se tratará del Magdaleniense y del Asiliense epimiolítico). Hoy sabemos, además, que las puntas de flecha pedunculadas de talla bifacial ya existían antes del Neolítico, formando sus representantes africanos más antiguos una parte característica del inventario ateriense epiprotolítico del Sáhara ${ }^{16}$.

El que lee con atención estas líneas acaso se sorprenda de que el término Tumbiense, que se repitió tantas veces en el primer capítulo, parece omitirse en el presente. Se trata de una cuestión terminológica de la que nos ocuparemos en seguida con detención. Por el momento nos limitamos a averiguar

15. Compárese el mapa en Movius, H. L.: Eorly Man and Pleirtoceme Srratigrapby in Southeris and Eastem Asia, en "Papers of the Peabody Museum of. Amer. Arch. and Ethn.", t. XIX/3. Cambridge (Mass.), 1944, p. 103. La cultura de guijarros trabajados ("pebble culture'), apartada por Movius, es probablemente sólo una variante de la cultura del hacha de mano.

16. Compárese ahora sobre el Ateriense, que se desarrolla de un Musteriense sahariano, Caton Thompen, G.: The Aterian Industry: Its Place and Siznificance in she Palsolitbic World. London, 1947. 
el resurgimiento del Tumbiense en el citado libro de Leakey y Owen. Owen se consagró desde 1928 al estudio del Paleolítico de Kenya, particularmente del Tumbiense, a cuya elucidación ha contribuído en gran medida. En cooperación con el famoso conocedor de la prehistoria africana Leakey y continuando las ideas de O'Brien, pudo clarificar la posición estratigráfica y la genealogía del Tumbiense estafricano. Ambos mantienen la concepción de O’Brien, según la cual en el Sangoense desarrollado ya se encuentran los prototipos del Tumbiense de Kenya, en primer lugar los picos de mano y ciertas puntas de lanza. Prefieren, por lo tanto, llamar Prototumbiense al Sangoense tardío. Además insisten en la afirmación de que el Tumbiense es una cultura de por sí, que posee un carácter propio. Consideran al Tumbiense como un derivado del Sangoense temprano, que a su vez es el resultado de una mezcla de Acheulense con Levalloisiense, y lo dividen en tres etapas: el Tumbiense antiguo, el medio y el tardío. Coinciden los resultados de Leakey y Owen con los de Breuil. También el Kaliniense es una cruza del Acheulense y Levalloisiense, aunque no puedo averiguar hasta donde son semejantes o idénticos el Sangoense y el Kaliniense, y si el Kaliniense culmina en una fase que corresponde al Prototumbiense de Kenya, lo que me parece muy probable. De todos modos, engendraron derivados estrechamente emparentados: el Tumbiense antiguo, medio y tardío en Kenya y el Djokociense, Lupembiense y Tshitoliense en el Congo. El Djokociense corresponde casi exactamente a mi Tumbiense antiguo, miolítico, cuya existencia la inferí en base tipológica. El Lupem.biense y Tshitoliense recuerdan mi Tumbiense de aspecto epipaleolítico y parecen coetáneos del Tumbiense medio de Kenya. El Tumbiense tardío de Kenya coincide posiblemente con mi Tumbiense neolitizado, el Leopoldiense y Ndoliense de Colette. Al establecer estas correlaciones ya hemos abordado la dilucidación del problema terminológico.

\section{III}

\section{EL TÉRMINO 'TUMBIENSE'}

En una carta, reproducida en el segundo de los citados artículos de Breuil ${ }^{17}$, dice Cabu que en su tesis de doctorado "condamnait le prétendu Tumbien, civilisation prétendúment apparentée au Mesolitbique de prétendus eleveurs de pores". Lamento verme obligado a suponer que Cabu no domine suficientemente la lengua alemana, como para entender el texto de mis

17. "Transactions of the R. Soc. of South Africa", t. XXX/2, 1944, p. 165. 
en el Protolítico - lo que es reconocido por la mayoría de los especialistas ${ }^{15}$ - sino también en el Miolítico, toda la zona tropical formó una relativa unidad, un círculo de vida cerrado, con relaciones bastante vivaces, y con tantos rasgos comunes, que bien puede hablarse de un círculo cultural. Las condiciones raciales refuerzan esta teoría, existiendo en ambos extremos del cíngulo tórrido una raza negroide, los negros de África y los melanesios de Oceanía, los últimos originalmente más. extendidos en el Asia meridional. No son idénticos, como no es idéntico enteramente su acervo arqueológico-cultural. Pero hay hechos que indican antiguas relaciones, cuyas peculiaridades por cierto tienen todavía que estudiarse más detenidamente.

Los nuevos conocimientos arrojan luz también sobre las relaciones del Congo con el resto de África. Solamente quisiera considerar aquí las conexiones con el Norte. Hoy ya no es posible ver el origen del Miolítico del Congo con la visual de Vaufrey. El trabajo bifacial no es ya el don de próximas culturas neolíticas, sino una herencia protolítica, como ya lo he conjeturado desde un principio. Las tendencias microlíticas se originan indudablemente en el Capsiense norteafricano, pero el hecho de comenzar a aparecer durante el Lupembiense no habla en favor de las fechas recientes que Vaufrey les atribuye. Por cierto, no es posible hoy día coordinar con absoluta seguridad las fases culturales y geológicas del África central y septentrional; pero las observaciones estratigráficas de Breuil, según las cuales el Lupembiense está situado en una terraza baja, que no representa la última de estos sistemas fluviales, comprueba una cierta antigüedad de su contenido arqueológico. El mismo Breuil correlaciona - sin duda correctamente- con el Lupembiense, el Middle Stone Age del África mèridional y una parte del Miolítico tardío de Europa (se tratará del Magdaleniense y del Asiliense epimiolítico). Hoy sabemos, además, que las puntas de flecha pedunculadas de talla bifacial ya existían antes del Neolítico, formando sus representantes africanos más antiguos una parte característica del inventario ateriense epiprotolítico del Sáhara ${ }^{16}$.

El que lee con atención estas líneas acaso se sorprenda de que el término Tumbiense, que se repitió tantas veces en el primer capítulo, parece omitirse en el presente. Se trata de una cuestión terminológica de la que nos ocuparemos en seguida con detención. Por el momento nos limitamos a averiguar

15. Compárese el mapa en Movius, H. L.: Eorly Man and Pleirtocene Stratigrapby in Southeri and Lastern Asia, en "Papers of the Peabody Museum of. Amer. Arch. and Ethn.", t. XIX/3, Cambridge (Mass.), 1944, p. 103. La cultura de guijarros trabajados ('pebble culture'), apartada por Movius, es probablemente sólo una variante de la cultura del hacha de mano.

16. Compárese ahora sobre el Areriense, que se desarrolla de un Musteriense sahariano, Caton Thompron, G.: The Atorion Industry: Its Place and Significance in she Palsolisbic World, London, 1947. 
el resurgimiento del Tumbiense en el citado libro de Leakey y Owen. Owen se consagró desde 1928 al estudio del Paleolítico de Kenya, particularmente del Tumbiense, a cuya elucidación ha contribuído en gran medida. En cooperación con el famoso conocedor de la prehistoria africana Leakey y continuando las ideas de O'Brien, pudo clarificar la posición estratigráfica y la genealogía del Tumbiense estafricano. Ambos mantienen la concepción de O'Brien, según la cual en el Sangoense desarrollado ya se encuentran los prototipos del Tumbiense de Kenya, en primer lugar los picos de mano y ciertas puntas de lanza. Prefieren, por lo tanto, llamar Prototumbiense al Sangoense tardío. Además insisten en la afirmación de que el Tumbiense es una cultura de por sí, que posee un carácter propio. Consideran al Tumbiense como un derivado del Sangoense temprano, que a su vez es el resultado de una mezcla de Acheulense con Levalloisiense, y lo dividen en tres etapas: el Tumbiense antiguo, el medio y el tardío. Coinciden los resultados de Leakey y Owen con los de Breuil. También el Kaliniense es una cruza del Acheulense y Levalloisiense, aunque no puedo averiguar hasta donde son semejantes o idénticos el Sangoense y el Kaliniense, y si el Kaliniense culmina en una fase que corresponde al Prototumbiense de Kenya, lo que me parece muy probable. De todos modos, engendraron derivados estrechamente emparentados: el Tumbiense antiguo, medio y tardío en Kenya y el Djokociense, Lupembiense y Tshitoliense en el Congo. El Djokociense corresponde casi exactamente a mi Tumbiense antiguo, miolítico, cuya existencia la inferí en base tipológica. El Lupembiense y Tshitoliense recuerdan mi Tumbiense de aspecto epipaleolítico y parecen coetáneos del Tumbiense medio de Kenya. El Tumbiense tardío de Kenya coincide posiblemente con mi Tumbiense neolitizado, el Leopoldiense y Ndoliense de Colette. Al establecer estas correlaciones ya hemos abordado la dilucidación del problema terminológico.

\section{III}

\section{EL TÉRMINO 'TUMBIENSE'}

En una carta, reproducida en el segundo de los citados artículos de Breuil ${ }^{17}$, dice Cabu que en su tesis de doctorado "condamnait le prétendu Tumbien, civilisation prétendüment apparentée au Mesolitbique de prétendus eleveurs de pores". Lamento verme obligado a suponer que Cabu no domine suficientemente la lengua alemana, como para entender el texto de mis

17. "Transactions of the R. Soc. of Suuth Africa", t. XXX/2, 1944, p. 165. 
trabajos de 1925 y 1926, y que probablemente no ha consultado mi Weltgeschicbte der Steinzeit. De otra manera no se explica el hecho de haber citado de modo tan inexacto mis ideas. Acabo de repetirlas brevemente en el primer capítulo de este escrito, de manera que toda persona puede apreciar mi verdadero pensamiento. Acaso no sea superfluo - sin embargo- acentuar aún más, que la cría de puercos es un elemento cultural que sólo coloco en combinación con la cultura protoneolítica del hacha cilíndrica (Walzenbeil); a mi parecer no tiene relación con las culturas miolíticas del hacha de mano. Tampoco advirtió Cabu que, aunque haya clasificado la gran masa del material del Congo a mi disposición como del Mesolítico (= Epimiolítico), ya vislumbré entonces las posibilidades de su articulación cronológica y el positivo carácter miolítico del mismo. Creo que conseguí bastante tomando en cuenta las circunstancias.

De estas rectificaciones debe apartarse la cuestión de si es o no oportuno mantener el término Tumbiense. Ya Colette lo rechazó, y Cabu aun con mayor decisión. Resulta más interesante que también mi apreciado amigo y colega Breuil propone la eliminación del nombre Tumbiense. Dice en el primero de sus artículos citados ${ }^{18}$ : "Comme le terme de chelléen a du, pour les prébistoriens avertis, être abandonné, car pretant d̀ mille confusions d'áges et de formes ${ }^{19}$, de même le terme tumbien, établi sur une table de musée, à partir de récoltes sélectionées de niveaux incertains, doit disparaitre pour faire place dे un vocabulaire mieux adapt' aux réalitt's typologiques et stratigrapbiques".

Un ataque muy recio lo dirigió el prominente especialista sudafricano Van Riet Lowe contra Leakey y Owen a causa de su empleo del término Tumbiense en el citado libro ${ }^{20}$. Estos autores censuraron mi elección del nombre por causas de prioridad: en su opinión yo hubiera debido escoger como yacimiento epónimo uno de los descubiertos por Stainier en el año 1899, porque el de Tumba fué publicado por Jacques un año después ${ }^{21}$.

18. Ibidem, p. 159.

19. Lo que no pudo impedir que el Primer Congreso Panafricano de prehistoria en Nairobi 1947, en presencia del Abbé Breuil, reemplazara el término Clacto-Abbevilliense por el de CbellesAcheul. 1946.

20. van RIBt Lowz, C.: Some Observations on the 'Tumbien' Culture, en "Man", t. XXVI,

21. No puedo consentir a esta demanda. Si se procediera rigurosamente conforme a 12 prioridad, probablemente se debería recurrir al artículo del Cap. Znoinsta: Un dge de la pierre au Congo, en "Bull. de la Soc. d'anthrop. de Bruxelles", t. VI, 1887/88. En la arqueología no tenemos reglas terminológicas semejantes a las de los biólogos, que fijan los congresos internacionales. Esto tiene sus buenas causas, porque es mucho más difícil establecer sanos principios para tales prescripciones, en la esfera de las ciencias culturales. De todos modos, no resulta razonable fundar denominaciones de culturas arqueológicas en la primera publicación del hallazgo respectivo, porque el autor a menudo no tiene la más mínima idea del alcance cultural c histórico de au material. El derecho de bautizar culturas es propio del que las reconoce por primero. 
Van Riet Lowe los reprueba por haber mantenido la palabra Tumbiense a pesar de reconocer este defecto de nomenclatura, y las objeciones basadas en dificultades que ofrece el mismo material arqueológico. Consentiría mantener el término Tumbiense solamente bajo la condición de que "the admixture of types on wbich the term was originally founded is resorted and rediscribed, and a selection of tools which belong to the same material culture is made and discribed as a basis on which to set this new culture and the term used to define it". Evidentemente el eminente colega paś por alto que la expresión Tumbiense fué creada para designar un grupo regional ya bien definido por mí con respecto a sus rasgos generales, necesitando sólo un estudio detallado en lo concerniente a su desarrollo.

A consecuencia de las opiniones críticas emitidas por autoridades científicas competentes, en el Congreso Panafricano de Prehistoria en Nairobi en enero de 1947, el término Tumbiense fué condenado a muerte, pero parece que no quiere morirse, y que hallara defensores no sólo antes, sino también después del solemne autodefé. Uno de ellos es Vaufrey, el investigador del Tumbiense de las colonias africanas francesas ${ }^{22}$. En un reciente trabajo presenta un material brillante que procede de la región entre el Senegal y el Niger en el Sudán occidental. Se trata de un Tumbiense fuertemente neolitizado, o sea de un Neolítico de tradición tumbiense, con hachas confeccionadas por retoques más o menos finos, a menudo con filo alisado, azadas, discos, puntas hoja de laurel del mismo estilo, escasos instrumentos sobre lasca, entre ellos un trapecio, y además hachas pequeñas enteramente pulimentadas, pulseras de piedra y cerámica. En las observaciones generales de su disertación, subraya la gran similitud de esta cultura con el Tumbiense del Africa central, el Campiñense europeo y el Bacsoniense de Indochina. Pone en relieve el hecho, sorprendente para él, que, casi en el mismo momento, en distintos puntos del mundo, junto con la construcción de casas, la explotación de la selva, la aparición de la agricultura, se reanude la técnica de la talla bifacial, desaparecida —salvo el episodio solutrense - desde el Paleolítico antiguo. Vaufrey defiende, además, el término Tumbiense como denominación adecuada para una cultura bien definida. Ciertamente su Tumbiense no es cabalmente idéntico al mío y al de Leakey y Owen. Es sólo la última ramificación del Tumbiense auténtico, un Neolítico de tradición tumbiense, un Paratumbiense como lo llama el mismo Vaufrey. Al escribir su tratado, evidentemente no pudo familiarizarse con las nuevas investigaciones del África central. Espero que mi

22. VAUTRBY, R.: Le Nélitbique para-toumbien, une civilisation agricole primitive du Soudan, en "Revue Scientifique", t. LXXXV, N॰ 3207, París, 1947. 
teoría de que la región tropical fué un foco del desarrollo miolítico de las culturas del hacha de mano, convencerá ahora también a este autor.

La interpretación del Tumbiense que da otro ilustre colega, coincide casi totalmente con mis propias ideas ${ }^{23}$. En un relato muy erudito Almagro expone la historia y el estado de la investigación paleolítica en África central y meridional, con especial consideración al Tumbiense. Cita un párrafo de una comunicación de Cabu a la Royal Society of South Africa, que dice: "El Tumbiense es condenado a desaparecer completamente para siempre jamás de la literatura científica y después de la condenación del mismo, pronunciada primero por mí y después por Goodwin y van Riet Lowe, su condenación en términos inequívocos ha sido de una vez para siempre confirmada por Henri Breuil". El tono apodíctico e impresionante de esta declaración nos resulta comprensible por ser acaso debido a vanidad personal y a una prevención nacionalista.

Escuchemos, en cambio, la voz imparcial de Almagro: "La argumentación de $\mathrm{H}$. Breuil de que los tipos atribuídos al Tumbiense aparecen a lo largo de los dos tercios de duración de la prehistoria del Congo, no debe ser considerada como fundamental, pues los tipos de Levallois, con o sin plano de percusión preparado, que dura tanto en Europa, deberían abandonarse por tal razón, ya que la técnica levalloisiense perdura después de haber desaparecido la cultura de Levallois, e incluso aparece en los yacimientos neolíticos de las sepulturas de Grimes. Sin embargo, a pesar de esto, a nadie se le ha ocurrido que por tal razón se debería cambiar el nombre de la cultura levalloisiense.

"Hay que admitir que mucho de lo que incluyó Menghín en su Tümbiense se ha venido a demostrar, con las investigaciones posteriores, que no pertenecía a esta cultura, pero por esto no debe abandonarse un nombre aceptado por todos, entre otros por $\mathrm{H}$. Breuil mismo y Mr. O'Brien, al estudiar la prehistoria de Uganda. Para todos el nombre de Tumbiense va unido a sus dos útiles esenciales: el pick y la punta de lanza o azagaya.

"Hoy, gracias al trabajo citado de Leakey y Archdeacon Owen, sabemos cómo se ha originado y desarrollado esta cultura en el Oeste de Kenya, desde su arranque en el Sangoan, a través del Prototumbiense, hasta el Tumbiense propio. Su trabajo sobre el origen y desarrollo de esta cultura, no deja lugar a dudas, así como la personalidad característica de su utillaje.

"Incluso Leakey cree que en los útiles proporcionados por el doctor Cabu a H. Breuil y a van Riet Lowe, y que sirvieron a éstos para expresarse como hemos indicado, hay pruebas suficientes para admitir una sucesiva

23. Almaaro, M.: El estado actual de la investigación dol Puleolítico inforior en el Africa regra y el problema de la revisión de la cultura tumbiense, en Ampurias, t. IX, 1947/43. 
evolución de esta cultura en el Congo, y que las culturas kaliniense y djokociense no son sino dos etapas distintas de la evolución del Tumbiense en el Congo.

"Hoy nadie puede sostener que el Congo no tenga otra Edad de Piedra que el Tumbiense, y a la vez claramente se puede ya asegurar que varias etapas del Tumbiense representadas en el Congo están extendidas también a los territorios de Uganda y del Oeste del Kenya.

"Leakey aconseja usar en vez de los nombres Kaliniense y Djokociense el nombre Tumbiense, y también a nosotros nos parece mejor conservar este nombre tan unido a un típico utillaje de piedra e ir aclarando su sentido y valor como han hecho en su trabajo los autores citados. Siempre será mejor que introducir nuevos términos, retener la palabra ya de antiguo aceptada y definir a la luz de nuestros actuales conocimientos la cultura tumbiense como una cultura típica y de gran dispersión en el África central, derivada del Sangoan y con muchas afinidades con la cultura de Fauresmith.

" Sin embargo, en las conclusiones del Congreso de Prehistoria de Africa celebrado este año en Nairobi parece ser se acordó abandonar este nombre, conclusión precipitada que no sabemos qué fortuna tendrá".

Como tercer defensor del Tumbiense se ha levantado Janmart en los dos últimos de sus estudios citados ${ }^{24}$. Descubrió en el distrito de Lunda (Angola) unas sesenta estaciones del Tumbiense medio y tardío, la más importante de ellas en Candala.

Acentuando su edad holocena, declara: "Si maintenant on me demandait d'integrer l'industrie de Candala dans una culture déja connue, je n'en vois qu'une qui me satisfasse: le Toumbien. On sait que le concept de la culture toumbienne a été attaqué violemment par d'eminent prébistorieins aul cours des dernieres années: ils refusent d'y voir autre chose qu'un assemblage occasionel d'objets de typologie et d'age disparates. Qu'ils me pardonnent de ne plus être de leur avis, au moins pour le moment".

Nada es preciso añadir a estas manifestaciones de tres especialistas de categoría, en cuanto a los hechos arqueológicos. Quisiera sólo establecer que en la ciencia prehistórica hubo varios casos análogos, en los que se procedió de una manera absolutamente distinta a la del Congreso Panafricano. De Morgan, p. ej., abarcó en su tiempo con el término Capsiense todo el Paleolítico superior del África del Norte. De investigaciones posteriores, sin embargo, resultó que esta región incluye una multitud de culturas miolíticas que no pueden clasificarse como una unidad. Sin embargo, el término Capsiense no quedó por tal hecho abolido, sino que se lo redujo

24. Cfr. Vaufrey, R.: Enzcore le Tozombien, en "L'Anthropologie", t. LIII, 1949, 'P. 342. 
a un valor apropiado, es decir a ciertas etapas del Paleolítico superior de la Argelia y Tunes. Es curioso que a pesar de ello, el mismo Congreso Panafricano extendió el nombre Capsiense al Miolítico del África oriental sin considerar las diferencias importantes entre ambas regiones.

\section{IV}

\section{CORRESPONDENCIAS DEL TUMBIENSE EN ASIA, EUROPA Y AUSTRALIA}

Por otra parte, los resultados sustanciales con respecto al génesis y desarrollo del Tumbiense son mucho más interesantes e importantes que esta discusión terminológica. A mi modo de ver, son de trascendencia extraordinaria para nuestro cuadro mundial de la historia de la cultura. Refuerzan mi visión de un gran conjunto de culturas miolíticas del hacha de mano extendidas sobre vastas porciones del Viejo y Nuevo Mundo, procedentes de las regiones tropicales.

Como ya hemos indicado, existe un segundo foco de culturas de esta clase, o sea la Indochina y la Indonesia, donde después de la aparición de mi Weltgescbicbte der Steinzeit aumentaron las investigaciones y excavaciones $^{25}$. En su brillante sumario de las averiguaciones arqueológicas en Indonesia, dice Heine-Geldern ${ }^{26}$ : "The mesolitbic cultures of Indonesia are really paleolitbic cultures which florished during the first millenia of the present geological period. However during their later phases they were more or less affected and tran'sformed by neolitbic influences coming in from the North. As a result, no clear-cut lines exist bere between Late Paleolitbic and Early Neolitbic". Es casi la misma situación que la del África central. Conocemos también en Indochina e Indonesia una etapa puramente miolítica de la cultura del hacha de mano (Keophayense y Lenggongense de mi terminología, Haobinhense I según Mlle. Colani), una etapa de transición (Bacsoniense I y Hoabinhense II) ya con hachas de filo alisado, y una etapa final, que es fuertemente neolitizada (Bacsoniense II y Hoabinhense III). Acaso sería prematuro trazar de una manera estricta un paralelo entre las fases centroafricanas y las del Asia sudoriental. Pero hay pocas dudas de que las tres fases tumbienses corresponden, no sólo en sus rasgos generales tipológicos, sino también

25. Maneuy, H.: La prébistoire dans Indochine, ete., París, 1931. - Patite, E.: L'Indacbine prebistorique, en "Rev. Anthrop.", t. XLVI, 1946. - Movivs, H. L.: The Stome Age of Burma, en "Transact. of the Americ. Phil. Soc.", N. S., t. XXXII/3, 1943.

26. Heina-Geldenn: Prebistoric Research in the Netberlands Indies, en "Science and Scientists in the Netherlands Indies" ", New York, 1945. 

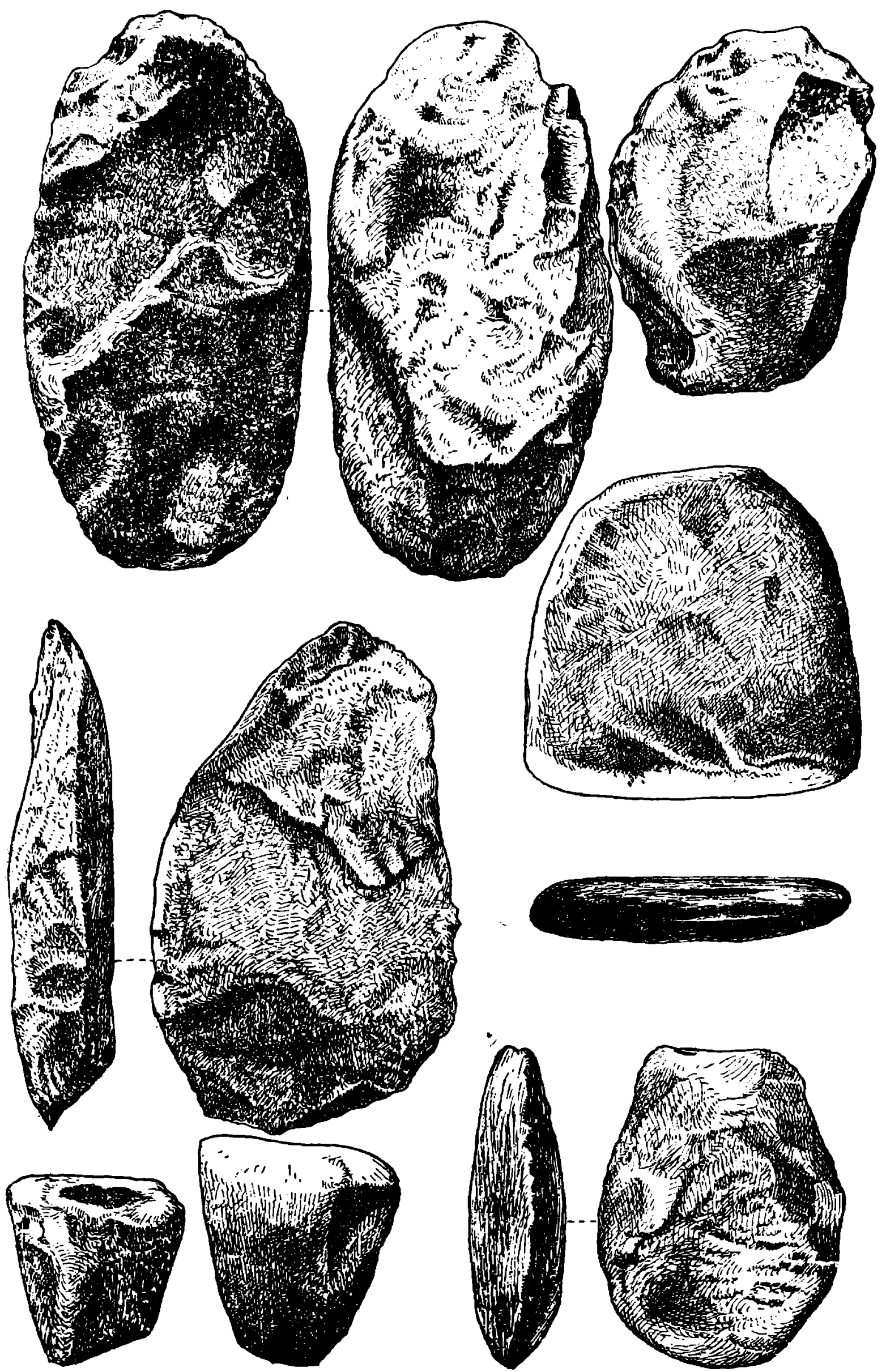

Fig. 2. - Hachas de mano y hachas miolíticas y epimiolíticas de Keophay y Dong-Thnoc (Tonkin, Indochina), según Mansuy. Todas las piezas son algo mayores que $2 / 1$. 
cronológicamente, a las tres de Indochina. Otro hecho de importancia transcendental es la coherencia del Mio-Epimiolítico del hacha de mano, en Asia, con la raza papua-melanesoide, atestiguada por muchos hallazgos ${ }^{27}$.

El gran problema - ya indicado- consiste en saber si existía una conexión genética entre ambos grupos tipológicamente tan cercanos: el africano y el asiático. No podemos resolverlo sin conocer, de una manera más satisfactoria, las regiones intermedias. Sabemos algo del Miolítico del Asia anterior y mucho de Siria-Palestina, pero en estos países parece faltar la cultura del hacha de mano miolítica. Esto no excluye, sin embargo, de modo alguno, un contacto entre el Miolítico centroafricano y el indochino; las relaciones pueden haberse efectuado a través de Arabia, Irán e India. Arabia e Irán son más o menos 'tierra incógnita' con respecto al Paleolítico y tampoco son suficientes las exploraciones en la India, a pesar de los excelentes trabajos realizados por de Terra y sus colaboradores ${ }^{28}$, pues se refieren en primera línea al Protolítico de la región del Indus. En todo caso es un hecho bien conocido que la India fué un centro de la cultura del hacha de mano protolítica. Además conocemos de este subcontinente hachas toscas, de alisado imperfecto, muy semejantes a los tipos del Tumbiense neolitizado. No están fechadas exactamente, pero es muy probable que representen un Epimiolítico neolitizado, aunque tal vez retrasado. Tampoco tenemos referencias a partir de su origen hasta el presente, siendo muy escasos en la India los materiales arqueológicos que se intercalan entre el Protolítico y el Neolítico. En ciertas regiones de la India, particularmente septentrionales, existía un Miolítico y Epimiolítico de lascas ${ }^{29}$; pero esto nada comprueba con respecto a las condiciones de otras partes de la península. De todos modos, podemos contar con la posibilidad de que también en vastas partes de la India floreció un Miolítico del hacha de mano. En este caso se disminuiría mucho la distancia entre el foco africano y el asiático de las culturas miolíticas del hacha de mano. Solamente nuevas investigaciones pueden llevar la solución definitiva del problema.

Un grupo tipológicamente relacionado con estas culturas es el Campiñense de la Europa septentrional, noroccidental y central; complejos epi-

27. van Strun-Calnenfers: The Melanesoid Civilisations of Eastern Asia, en "Bull. of the Raffles Museum", Singapore, Ser. B. 1, 1936. - Wastr, J.: Präbistoriscbe Menschenreste aus dem Muscbelbügel von Binjai-Tamieng in Nord-Swmatra, en "Kultur und Rasse; Festschrift f. Otto Reche", München-Berlín, 1939; cfr. Heine-Geldern l. c.

28. Thron, H. de and Patbroon, P.: Studies on tbe Ice Age in India and Associated Human Culimres, Carnegie Inst., Wáshington, No 493, 1939. - Teilmard de Chardin, P.: Notes sur la palfontologie bumaine on Asie meridionale, en "L'Anthropologie", t. XLVII, 1937, XLVIII, 1938.

29. Menomín, O.: Weltgescbichte der Steinzeit, Viena, 1931, p. 197. - TodD, K. R.: A Microlitbic Culture in Eastern Mysore, en "Man", t. XLVIII, 1948. - Sanral, H. D.: Invessigation into Prebistoric Archacology of Gujarat, Baroda, 1946. - SANKarl, H. D. AND Karvz,' I.: Eerly Primitive Microlisthic Culture and Pcople of Gmjorat, en "American Anthrop.", t. LI, 1949. 
miolíticos muy semejantes existen también en la Europa sudoriental (Hungría y Rumania), hecho que sugiere la presunción de la inmigración del Campiñense desde el Sureste. No deseo explayarme aquí sobre la cuestión campiñense, ventilada por mí ya varias veces $^{30}$, pero vuelvo a insistir en mi teoría de que la semejanza del Campiñense con el Tumbiense no es una mera convergencia, porque se basa en una parentela genética. Los que afirman que el Campiñense es una facies minera del pleno Neolítico, pasan por alto una multitud de indicios que hablan en contra de tal suposición; en primera línea el hecho que los tipos campiñenses - el pic y el tranchet- ya aparecen en estratos preneolíticos, postglaciales y en conjuntos como el Maglemosiense. Por lo demás, la significación del Campiñense para nuestro problema no es grande, porque no evolucionó en Europa, a pesar de que ya tuvo un antecesor miolítico en el Protosolutrense y Predmostiense de Hungría y Moravia ${ }^{31}$. No existía, sin embargo, un contacto directo entre estas dos oleadas europeas de la cultura del hacha de mano, que están separadas por el Magdaleniense.

Una ramificación miolítica de la cultura del hacha de mano, la encontramos también en Australia. Somos deudores a Fürer-Haimendorf por su profundo estudio de este material tan complicado ${ }^{32}$. Sacamos de su trabajo las siguientes conclusiones (p. 452): "Mientras que los instrumentos de las mesetas centrales de Australia recuerdan en parte tipos protolíticos, tiene la cultura de la Isla de Canguro todas las características de una facies del hacha de mano miolítica. Relacionadas con estas culturas están la capa más antigua de Tartanga así como la de otros yacimientos, ante todo las hachas de mano y picks hallados en la orilla de Nueva Gales del Sur. Correlaciones exactas con esta facies se encuentran en las culturas más antiguas del Tonquin, Malaca y Sumatra. Sin duda representa la rama más meridional de una cultura antiguamente difundida sobre todo el Asia sudoriental". Añade que se trata, según la evidencia de las excavaciones en Indochina e Indonesia, de una cultura que no conocía el cultivo desde un principio. Pero no me parece justificada esta afirmación; es más bien una mera conclusión ex silencio; pues la ausencia de claros indicios del cultivo en las culturas de Keophay y Lenggong no es una prueba segura de que en efecto faltaron plantas cultivadas. La alterabilidad de substancias vegetales hace muy díficil comprobar arqueológicamente la existencia del cultivo o lo

30. Mangrín, O.: Die mesolitbiscbe Kulturentwicklung in Europa, en "XVII. Bericht d. Rörn.German. Kommission", Frankfurt 2. M., 1927; del mismo autor: Weltgescbicbte der Steinzeit, Vien2, 1931, Pp. 210, 216, 257, 269.

31. Menarín, O.: Weltgescbichte der Steinzeit, Viena, 1931, p. 211.

32. Fürra-Hammanorf, CE. v.: Zer Urgescbicbte Australiews, en "Anthropos", t. XXXI, 1936, p. 1,433 . 
contrario. Además no queremos pasar por alto que una clase de pequeños metates $^{33}$ ya aparece muy temprano en Indochina, y un tipo bien desarrollado de este instrumento en el Bacsoniense antiguo. Por lo demás, también Fürer-Haimendorf llegó a la conclusión de que las culturas del hacha de mano miolíticas de Indochina y Australia representan el acervo arqueológico de un gran complejo matriarcal, por cierto no el de la "cultura de las dos clases", que él combina con la oleada que efectuó la 'neolitización' de Australia.

La neolitización es un proceso que, como hemos visto, se realizó en todos los centros de la cultura del hacha de mano considerados hasta ahora. Plantea difíciles e importantes problemas. ¿Fué la neolitización un desenvolvimiento interno que afectó todas las ramas de esta cultura? Admitiendo esta posibilidad, ¿se produjo o no, de manera independiente en cada caso? ¿O fué la neolitización el resultado de influjos de culturas más avanzadas, protoneolíticas y neolíticas? ¿Fueron - los mismos- unitarios o heterogéneos? No podemos entrar aquí en la discusión detallada de estas cuestiones. Pero quisiera subrayar que en cuanto se trata del Campiñense, es de excluir la admisión de que su neolitización, que se manifiesta más ciaramente en los concheros de Dinamarca (cultura de Ertebölle, de Kjökkenmöddinger), tenga relación directa con la del Tumbiense o del Hoabinhense. Y es también extremadamente improbable que existiera en este punto una interdependencia entre África e Indochina. Debemos, pues, aceptar que estos tres grupos emparentados básicamente se neolitizaron por acontecimientos independientes, si bien en parte condicionados por las mișmas fuentes, entre las cuales la cultura protoneolítica del hacha cilindriforme (o un derivado de la misma) desempeñó un papel sobresaliente. Con respecto a Australia, en cambio, inclínase Fürer-Haimendorf, rehusando la opinión de Heine-Geldern, hacia mi proposición que pone la neolitización de este continente en un nexo inmediato con la de Indochina, lo que significatía que no sólo una facies antigua del tipo Keophayense, sino también otra, ya neolitizada, como el Bacsoniense, irradió directamente a Australia, a pesar de que huellas de una oleada del hacha cilíndrica son allá perceptibles. Referente al sistema de las dos clases matrimoniales, me parece lo más probable que no corresponde ni a la cultura del hacha de mano ni a la del hacha cilindriforme, sino que es efecto de una mezcla entre la primera y la cultura miolítica de lascas, que es el sedimento arqueológico de caza-

33. Palabra procedente del vocablo nahua metlatl, que indicaba unos utensilios de piedras usados - como se usan todavía- para la molienda del maíz y otros granos, así como en la claboración del chocolate. Sus formas más complejas tienen generalmente tres pies y una superficie algo acanalada e inclinada. 
dores avanzados, probablemente los portadores primitivos del totemismo. La cultura miolítica del hacha de mano en su estado puro, como mejor la representan el Djokociense del Congo y el Keophayense de Indochina, debe combinarse con el complejo más antiguo de plantadores matriarcales, bautizado de una manera muy atinada "cultura de la azada" por Imbelloni ${ }^{34}$. Muchos expertos arqueólogos aceptan que las hachas de mano plano-convexas, los picks y tipos semejantes, representan azadas que, provistas de mango, servían a la labranza y en parte quizá a la minería (excavación de materias primas). Su forma plano-convexa indica que fueron enmangadas transversalmente, es decir, con el filo en ángulo recto con respecto al mango. Quisiera poner en relieve que los labriegos de azada utilizan semejantes instrumentos aún hoy en día, aunque reemplazando la hoja de piedra por una de hierro.

\section{V}

\section{LA CULTURA DEL HACHA DE MANO MIOLÍTICA EN AMÉRICA}

En mi Weltgeschicbte der Steinzeit, p. 225 y sigs. escribí lo que transcribo: "Hay en ambas Américas una considerable cantidad de artefactos que pueden calificarse, desde el punto de vista tipológico, como derivados de la cultura del hacha de mano. Por desgracia, es difícil establecer su fecha geológica. Lo único seguro es que no se trata de objetos protolíticos. Tampoco es probable que pertenezcan al Miolítico antiguo, pues no parece que el camino de América estuviera libre de hielo en aquella época. Por lo tanto, estos artefactos podrían pertenecer al Miolítico tardío. Por no contarse con la existencia de una cultura miolítica del hacha de mano, la posición histórica de estos restos quedó mal entendida hasta la fecha. Ante todo, desde nuestro punto de vista, se vierte nueva luz sobre un conocido complejo arqueológico americano. Son los hallazgos de Trenton, de los cuales hace poco P. Sarasin se ha vuelto a ocupar detenidamente ${ }^{35}$. En las gravas del río Delaware se halló hace unos decenios cuantiosos instrumentos pétreos, cuya edad y clasificación causaron muchas discusiones, sin que se llegara a una conclusión. Se trata en lo esencial de una cultura del hacha de mano en un estado avanzado. Su descubridor Abbott y muchos

34. Imbrilon, J.: Epítome de culturología, Biblioteca "Humanior", Serie A, tomo 1, Buenos Aires, 1936, Pp. 105-109.

35. Sarasin, P.: Zer Frage von der präbistoriscben Besiedlung von Amerika, en "Denkschr. d. Scbweiz. Naturf. Ges.", t. LXIV, 1928, p. 233. 
contrario. Además no queremos pasar por alto que una clase de pequeños metates $^{33}$ ya aparece muy temprano en Indochina, y un tipo bien desarrollado de este instrumento en el Bacsoniense antiguo. Por lo demás, también Fürer-Haimendorf llegó a la conclusión de que las culturas del hacha de mano miolíticas de Indochina y Australia representan el acervo arqueológico de un gran complejo matriarcal, por cierto no el de la "cultura de las dos clases", que él combina con la oleada que efectuó la 'neolitización' de Australia.

La neolitización es un proceso que, como hemos visto, se realizó en todos los centros de la cultura del hacha de mano considerados hasta ahora. Plantea difíciles e importantes problemas. ¿Fué la neolitización un desenvolvimiento interno que afectó todas las ramas de esta cultura? Admitiendo esta posibilidad, ¿se produjo o no, de manera independiente en cada caso? ¿O fué la neolitización el resultado de influjos de culturas más avanzadas, protoneolíticas y neolíticas? ¿Fueron - los mismos- unitarios o heterogéneos? No podemos entrar aquí en la discusión detallada de estas cuestiones. Pero quisiera subrayar que en cuanto se trata del Campiñense, es de excluir la admisión de que su neolitización, que se manifiesta más claramente en los concheros de Dinamarca (cultura de Ertebölle, de Kjökkenmöddinger), tenga relación directa con la del Tumbiense o del Hoabinhense. $Y$ es también extremadamente improbable que existiera en este punto una interdependencia entre África e Indochina. Debemos, pues, aceptar que estos tres grupos emparentados básicamente se neolitizaron por acontecimientos independientes, si bien en parte condicionados por las mișmas fuentes, entre las cuales la cultura protoneolítica del hacha cilindriforme (o un derivado de la misma) desempeñó un papel sobresaliente. Con respecto a Australia, en cambio, inclínase Fürer-Haimendorf, rehusando la opinión de Heine-Geldern, hacia mi proposición que pone la neolitización de este continente en un nexo inmediato con la de Indochina, lo que significaría que no sólo una facies antigua del tipo Keophayense, sino también otra, ya neolitizada, como el Bacsoniense, irradió directamente a Australia, a pesar de que huellas de una oleada del hacha cilíndrica son allá perceptibles. Referente al sistema de las dos clases matrimoniales, me parece lo más probable que no corresponde ni a la cultura del hacha de mano ni a la del hacha cilindriforme, sino que es efecto de una mezcla entre la primera y la cultura miolítica de lascas, que es el sedimento arqueológico de caza-

33. Palabra procedente del vocablo nahua metlatl, que indicaba unos utensilios de piedras usados - como se usan todavía- para la molienda del maíz y otros granos, así como cn la claboración del chocolate. Sus formas más complejas tienen generalmente tres pies y una superficie algo acanalada e inclinada. 
dores avanzados, probablemente los portadores primitivos del totemismo. La cultura miolítica del hacha de mano en su estado puro, como mejor la representan el Djokociense del Congo y el Keophayense de Indochina, debe combinarse con el complejo más antiguo de plantadores matriarcales, bautizado de una manera muy atinada "cultura de la azada" por Imbelloni ${ }^{34}$. Muchos expertos arqueólogos aceptan que las hachas de mano plano-convexas, los picks y tipos semejantes, representan azadas que, provistas de mango, servían a la labranza y en parte quizá a la minería (excavación de materias primas). Su forma plano-convexa indica que fueron enmangadas transversalmente, es decir, con el filo en ángulo recto con respecto al mango. Quisiera poner en relieve que los labriegos de azada utilizan semejantes instrumentos aún hoy en día, aunque reemplazando la hoja de piedra por una de hierro.

\section{V}

\section{LA CULTURA DEL HACHA DE MANO MIOLÍTICA EN AMÉRICA}

En mi Weltgescbicbte der Steinzeit, p. 225 y sigs. escribí lo que transcribo: "Hay en ambas Américas una considerable cantidad de artefactos que pueden calificarse, desde el punto de vista tipológico, como derivados de la cultura del hacha de mano. Por desgracia, es difícil establecer su fecha geológica. Lo único seguro es que no se trata de objetos protolíticos. Tampoco es probable que pertenezcan al Miolítico antiguo, pues no parece que el camino de América estuviera libre de hielo en aquella época. Por lo tanto, estos artefactos podrían pertenecer al Miolítico tardío. Por no contarse con la existencia de una cultura miolítica del hacha de mano, la posición histórica de estos restos quedó mal entendida hasta la fecha. Ante todo, desde nuestro punto de vista, se vierte nueva luz sobre un conocido complejo arqueológico americano. Son los hallazgos de Trenton, de los cuales hace poco P. Sarasin se ha vuelto a ocupar detenidamente ${ }^{35}$. En las gravas del río Delaware se halló hace unos decenios cuantiosos instrumentos pétreos, cuya edad y clasificación causaron muchas discusiones, sin que se llegara a una conclusión. Se trata en lo esencial de una cultura del hacha de mano en un estado avanzado. Su descubridor Abbott y muchos

34. Imarimon, J.: Epítome de culturología, Biblioteca "Humanior", Serie A, tomo 1, Buenos Aires, 1936, PP. 105-109.

35. Saranin, P.: Zur Frage von der präbistoriseben Besiedlung von Amerika, en "Denkschr. d. Schweiz. Naturf. Ges.", t. LXIV, 1928, p. 233. 
otros la consideraron como Acheulense americano ${ }^{36}$. Pero los geólogos negaron la edad cuaternaria de las respectivas gravas. Esta opinión parece prevalecer aún hoy. Podría presumirse, por cierto, que los artefactos de Trenton descansan en un depósito secundario y fueron acarreados desde capas más antiguas en las gravas postglaciales. Pero a tal suposición se oponen distintas circunstancias, como explica Sarasin. Por ello, existen sólo dos posibilidades para establecer la fecha de estos hallazgos. Son neolíticos, o aun más recientes, y productos de los indios precolombianos, como pretende Sarasin, o tienen que ser atribuídos a una oleada tardío-miolítica, eventualmente epimiolítica, lo que implica reconocerlos como equivalentes americanos del Campiñense, Tumbiense, etc. No puedo decidirme entre estas dos eventualidades, sin antes examinar personalmente todos los hallazgos y estratos. Pero, sea como fuera, la cultura de Trenton siempre debe ser entendida sólo como ramificación de la cultura del hacha de mano miolítica, aun considerando que posiblemente sobrevivió hasta tiempos recientes. No puede seguirse el conjunto de semejantes complejos arqueológicos de Norteamérica en este libro. Sin duda hay muchos. Y lo mismo vale para la América del Sud. Aquí muchos sambaquís contienen una industria que no puede distinguirse del Miolítico con hachas de mano del Viejo Mundo. Desde luego, su edad generalmente se desconoce. Parece, sin embargo, que un yacimiento sudamericano fué datado geológicamente. Cerca del arroyo Observación, que desemboca en la Bahía de Mazaredo en la Patagonia, Outes descubrió en una capa de guijarros de 5 metros de profundidad, separada con claridad de depósitos indios más recientes, dos artefactos paleolíticos; uno de ellos es una buena hacha de mano ${ }^{37}$. Es difícil conjeturar una edad protolítica para estos objetos, aunque el estrato no pueda datarse exactamente. Tendría enorme importancia para la historia cultural más antigua de América, que las ideas aquí sugeridas pudiesen confirmarse por medio de observaciones precisas".

Desde que publiqué lo que antecede ha habido un gran adelanto en la investigación del Paleolítico americano, tanto en lo que se refiere a la geocronología, como a la arqueología. Desapareció el anatema de Hrdlička contra el hombre cuaternario en este continente, y nadie duda hoy de la existencia del Miolítico americano, si bien es tal vez más reciente que el de Europa. Entre las facies miolíticas americanas conocidas hasta ahora

36. Aввотт, Сн. C.: Primitive Industry... of the Native Races of the Nortbern Atlentic Seabond of America, Salem, Mass., 1881. - WiLson, TH.: La baute ancienneté de l'bomme dans l'Amérique di Nord, en "L'Ánthropologie", t. XII, 1901, p. 297.

37. Outra, F. F.: La edad de la piodra en la Patagenia, en "Anales del Museo Nacional de Buenos Aires", t. V, 1905, p. 203. 
se destacan los complejos de Sandía, de Folsom y de Yuma, los tres de carácter solutroide. Sandía parece más antigua que Folsom, desde el punto de vista geológico; muestra además una clara afinidad con el Miolítico solutroide de la región de Irkutsk en Asia nororiental, mientras que Folsom y Yuma tienen un aspecto más autóctono, especialmente Folsom, lo que significa que constituyen el resultado de un desenvolvimiento americano interior $^{38}$. A mi modo de ver las facies solutroides de Europa y Asia septentrional se originaron en una mezcla entre culturas de lascas de derivación aurignacoide y culturas del hacha de mano, siendo culturas de cazadores avanzados las primeras, y de primitivos plantadores las últimas. No puedo explayarme aquí con respecto a las comprobaciones de esta teoría, y me limito a aludir a las explicaciones respectivas de mi Weltgescbicbte der Steinzeit, pp. 151, 200, 257, 262, 499. Me apoyo, en mis deducciones, no sólo en la tipología de los artefactos pétreos, sino también en toda una cantidad de instrumentos óseos y además elementos de la cultura intelectual, que se manifiestan en Europa oriental como privativos de un ciclo cultural en absoluto distinto del de lascas. Quisiera, sin embargo, recalcar que tales mestizajes dieron facies en lo esencial cazadoras desde el punto de vista económico, tanto en América como en Europa y Asia. Con respecto a la vida intelectual, en cambio, estas facies en el Viejo Mundo ostentan muchos rasgos que coinciden con el patrimonio de las culturas plantadoras y matriarcales más primitivas. Representantes clásicos de este género de culturas mezcladas, son el Solutrense y el Magdaleniense de Europa central y occidental ${ }^{39}$. Es permitido pensar, por lo tanto, que el grupo folsomoide (Sandía, Folsom, Yuma) constituye la base de culturas indias que combinan rasgos matriarcales con la economía de cazadores.

Existe en América, sin embargo, un segundo grupo de facies miolíticas

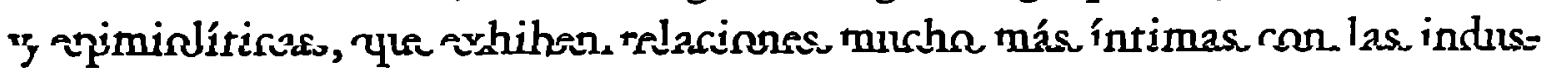
trias del hacha de mano. Una de las más importantes se llama cultura de Cochise $^{40}$. Se divide en tres etapas: la de Sulphur Spring, la de Chiricuahua y la de San Pedro. La primera es miolítica tardía, más o menos coetánea con el complejo de Folsom, y floreció en Arizona y las partes colindantes de Nuevo México. Ofrece el aspecto de un Miolítico de hachas de mano

38. Conforme a las noticias particulares que recibí de los Estados Unidos, se descubrió en el último tiempo un yacimiento con puntas Yuma, que pertenece al interstadial entre la glaciación Wisconsin II y III. La facies de Yuma es, por consiguiente, tal vez más antigua que la de Folsom, lo que no puede sorprendernos, considerando la analogía con el Solutrense y Magdaleniense europeos.

39. Mangrín, O.: Weltgescbicbte der Steinzeit, Vien2, 1931, PP. 152, 263.

40. Sayles, E. B.: An Arcbaeological Survey of Cbiricuabua, MÉxico, Gila Pueblo, en "Medallon Paper 22", Globe (Arizona), 1936. - SAYLes, E. B. Y ANTes, E.: Tbe Cocbise Culture, Gila Pueble, en "Medallon Paper 29", Globe (Arizona), 1941. 
algo degenerado. Entre sus escasos instrumentos tallados tienen especial interés para nosotros los tipos plano-convexos con retoque bastante tosco, que servían para golpear, cortar, etc. Más frecuentes son los metates (piedras para moler) y las manos correspondientes. No cabe duda que esta gente se alimentó en gran medida de materias vegetales. Los especialistas sostienen que no se trata de verdaderos plantadores, sino sólo de recolectores de plantas. Volveré sobre esta cuestión más adelante. La etapa de Chiricuahua es definidamente epimiolítica y manifiesta un aumento de las características que asignan la cultura de Cochise a un complejo plantador con hachas de mano.

Un grupo arqueológico lo más estrechamente vinculado a la cultura del hacha de mano es el de que se ocupa Bryan en unos artículos ${ }^{41}$ desde el punto de vista arqueológico y geológico, de manera que sobre su edad mesolítica no cabe duda. Uno de sus centros es el Cerro Pedernal en el lado septentrional de la montaña de Jemez en Río Atriba Country, New Mexico. La cultura de Los Encinos, como se llama esta facies, abarca hachas de mano, picks, puntas en forma de hojas e instrumentos sobre lascas, conjunto que, tipológicamente, pudiera también proceder del Congo.

Se descubrieron conjuntos arqueológicos similares en la región de $\mathrm{Abi-}$ lene, Texas ${ }^{41 a}$. Aquí pudo establecerse una serie de cinco niveles culturales. Leighton exagera probablemente la edad geológica de estos descubrimientos, al colocar los estratos más antiguos en la edad anterior a la última glaciación; en realidad deberían considerarse pertenecientes a ella y a su terminación ${ }^{42}$. Los horizontes más ințeresantes son el segundo y el tercero, el 'Abilene Branch' y la 'Edwards Plateau Culture'. El 'Abilene Branch' contiene artefactos líticos con retoque bifacial, realizado por percusión. El tipo más característico es un instrumento, al que Leighton llama raspador, pero en base a la figura inserta en su trabajo preferiría calificarlo un hacha de forma triangular con filo producido por un golpe transversal, semejante a ciertas hachas del Neolítico de Palestina. En la cultura del Edwards Plateau aparece el retoque por presión y metates.

En el círculo de estas culturas puede colocarse también Trenton, New Jersey ${ }^{43}$, si bien el material respectivo ofrece cierto aspecto folsomesco.

41. Bryan, K.: Prebistoric Quarries and Implements of Pre-Amerindian Aspect in New Mexico, en "Science" mt. LXXXVII, 1938; del mismo autor: Stone Cultures near Cerro Pedernal and Tbeir Geological Antiquity, en "Bulletin of Texas Arch. and Palaeont. Soc.", t. XI, 1939.

L2 Plata.

Agradezco el conocimiento de la bibliografía al colega A. R. González, del Museo de

41 a. Lniohton, M. M.: Geological Aspects of the Findings of Primitive Mon, near Abilone, Texas, Gila Pueblo, en "Medallon Paper 24", Globe (Arizona), 1936.

42. Martinez del Río, P.: Los origenes amoricenos, 2 ed., México, 1943, p. 175.

43. Volx, E.: The Archacology of the Delaware Valley, en "Papers of the Peabody Museum 
El yacimiento de Abbotts Farm se divide en tres estratos. La capa superficial contiene un depósito arqueológico indio, perteneciente a los Lenapé (Delaware). La capa media, cuyo espesor alcanza parcialmente $2 \mathrm{~m}$., es precerámica y dió hachas de mano, a menudo plano-convexas, puntas en forma de hojas y puntas de lanza (o de flecha) con ancho pedúnculo, tipo muy antiguo en América, como lo comprueban las observaciones estratigráficas de Bird en Patagonia ${ }^{44}$. La capa más baja, divisible en dos niveles diferentes, abarca restos faunísticos glaciales y guijarros preparados por el hombre. La capa media, por consiguiente, se acumuló en una fase de transición entre la última glaciación y la actualidad; la industria que incluye es, pues, epimiolítica y no neolítica como pretenden Holmes y Sarasin ${ }^{45}$.

Existen muchos yacimientos en el Sudoeste de los Estados Unidos, que pertenecen al grupo cochisoide, p. ej. los hallazgos de la cuenca de Pinto, California ${ }^{46}$. Posiblemente podrían insertarse aquí los descubrimientos de los altiplanos occidentales de Norteamérica, que Renaud relaciona con Trenton ${ }^{47}$. Pero no puedo ocuparme de estos materiales por falta de bibliografía.

No cabe duda que el complejo mexicano llamado cultura de Chalco por de Terra, debe incluirse en este grupo. De Terra lo compara con los hallazgos de la cuenca de Pinto, Chriricuahua, etc., atribuyéndole edad epimiolítica (8.000-3.000 a. de C.). La cultura de Chalco abarca muchos artefactos de retoque bifacial, a menudo plano-convexos, evidentemente derivados del hacha de mano, aunque algo degenerados. Tambien de Terra piensa que se trata sólo de recolectores de plantas y cazadores de animales pequeños ${ }^{48}$.

of Americ. Anthrop. and Ethnol.", Cambridge (Mass.), t. V, 1911. - Prabody, Ch.: A Summary of tbe Arcbacology of Trenton, en "XVIII Congr. intern. American", (Londres, 1912), 1913. - Spisr, L.: Tbe Trenton Argillite Culture, en "Anthrop. Papers of the Americ. Mus. of Nat. Hist.", t. XXII/4, 1918. - Breve sumario en Pericot y GArcíA, L.: América Indigena I, Barcelona, 1936, p. 257.

44. BIro, J.: Antiquity and Migrations of tbe Early Inbabitants of Patagonia, en "The Geographical Review", t. XXVIII, 1938; del mismo autor: Before Magellan, "Natural History", t. XLI, 1938.

45. No me parece justificada la estimación de Trenton por Hosm rs, W. H.: Handbook of Aboriginal American Antiquities, en "Bureau of American Ethnology", Bull. 60, 1a. parte; Smithson Inst., Wáshington, 1919, p. 76 y Pitfalls of the Paleolithic Theory in America, en "XX Congr. intern. American.", Río de Janciro, 1922, t. II, 1928, p. 171. Por lo demás, me parecería muy deseable una revisión de este yacimiento con métodos modernos. Pude ver el sitio en oportunidad del Symposion of Early Man en Philadelphia, 1937, y llamé la atención sobre el hecho que está en peligro de destrucción total.

46. Camperle, W. H.: Tbe Pinto Basin Site, en "Southwest Museum Papers", No 9, Los Angeles, 1935.

47. Ranadd, E. B.: The Arcbaeological Survey of the High Western Plaines, en "7th. Rep., Southern Wyoming and S. W. Dakota", Denver, 1936. Sólo conozco este trabajo por la reseña de VAuprex, R., en "L'Anthropologie", t. XIVII, 1947, p. 660.

48. de Terra, H., Rombro, J., Strberart, T. D.: Tepexpen Man, en "Viking Fund Publications in Anthropology", No 11, New York, 1949, p. 72. 
Si dirigimos nuestra atención a la América del Sud, podemos establecer que aquí también existen ambos grupos mio-epimiolíticos. El grupo solutroide-folsomoide está aún escasamente representado y seguramente sólo por falta de exploración. Ya dispongo de varias informaciones sobre puntas del tipo Folsom, halladas en la Argentina y en Chile; pero es menester revisarlas. Aquí quisiera aludir sólo a una punta folsomesca, fragmentada, que Bird excavó en la capa más baja de la cueva de Fell en el valle del Río Chico, Terr. de Santa Cruz, Patagonia ${ }^{49}$. Puntas del tipo Yuma aparecen a veces entre los materiales líticos de la Patagonia ${ }^{50}$, hasta ahora, por cierto sin documentación estratigráfica, como también la de Bejuma en Vene-

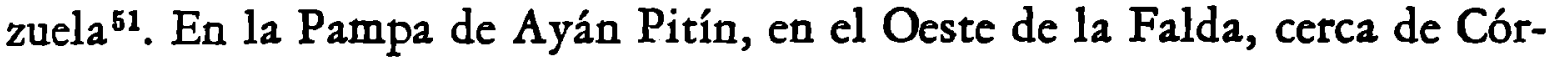
doba, el ingeniero Coronel Aníbal Montes descubrió un yacimiento precerámico, estratificado, cuyos instrumentos, confeccionados en cuarcita cristalina, se componen en su mayoría de puntas hoja de laurel y formas emparentadas. Sin querer adelantarme a la investigación definitiva, creo que se trata de un conjunto epimiolítico de parentesco folsomoide.

Con referencia a las culturas del hacha de mano miolíticas, a las que se consagra el principal interés de este artículo, disponemos de un material más rico, en primer lugar relatos antiguos de gran valor, aunque poco apreciados hasta la fecha. El pastor Kunert dirigió entre 1890 y 1900 varias cartas sobre hallazgos arqueológicos en el estado de Río Grande del Sud (Brasil) al profesor R. Virchow, en Berlín;la última de ellas tiene especial alcance para nosotros ${ }^{52}$. Escribe: "Existen aquí, sin embargo, auténticos artefactos paleolíticos, piedras de talla tosca, pero conveniente, que'se distinguen en cuanto a la forma y el tamaño de las piedras retocadas de períodos posteriores. También es posible establecer que pertenecen a la más antigua etapa de nuestra edad de piedra. Ya desde hace muchos años hallé grandes piedras de esta clase, retocadas como las puntas de flecha, preferentemente en el altiplano del Morro de Diabo; pero en aquel entonces no pude reconocer su importancia. Algunas de estas piedras, casi del espesor de un brazo, quedaron tan descompuestas, que las pude raspar con la uña y romper sin más, experimento que me valió la destrucción de unos bellos ejemplares; otras, de un material más resistente, se conservaron en buen estado... Desde el principio clasifiqué estas armas como neolíticas, ya que las encontré en un distrito en que se hallaron objetos del Neolítico tem-

49. Bird, J.: l. c.

50. Outrs, F. F.: l. c., p. 407, fig. 125 (hallazgo de Punta Atlas, Terr. del Chubut). t. $I / 1,1945$.

52. Kungat, A.: Riograndenser Paldolithen, en "Zeitschr. f. Ethnol.", t. XXXII, 1900, Verh., p. 348. 
prano, es decir grandes hachas cilíndricas de un tipo muy peculiar. Al desmontar este lugar (plano del Morro de Diabo sobre el río Forromeco) aparecieron con la primer pasada del arado cinco artefactos paleolíticos; yacían a mayor profundidad que los objetos del Neolítico antiguo, que hube encontrado antes... superficialmente en una capa plana de arcilla. Las cinco piedras, talladas de manera rudimentaria, se hallaron en un hoyo poco profundo de más o menos un pie. La formación de una capa de este espesor necesita mucho tiempo, especialmente en el altiplano de una montaña. Los objetos neolíticos y paleolíticos, hallados anteriormente en la vecindad, quedaron muy descompuestos, mientras que las piedras del susodicho hoyo no muestran una descomposición avanzada, con excepción de una ligera incrustación, causada por la arcilla. Algunos fueron labrados con un material duro como vidrio, que no acepta incrustación y no se corrompe fácilmente; otros fueron fabricados con tocas menos resistentes. La mayor parte de las piedras fué sacada del próximo riachuelo, cuyos guijarros no son tan rodados como los de los ríos más grandes".

De las explicaciones de Kunert resulta -además- que pudo identificar otros yacimientos, cuya posición en el suelo y tipología permitieron suponer que pertenecen al paleolítico; se refiere asimismo a hachas talladas con filo pulimentado, que probablemente corresponden a los sambaquí arcaicos de San Paulo, de los que me ocupo más adelante. Kunert no las separb de las hachas cilíndricas, pero ya reconoció la edad relativamente antigua de las últimas. En su ensayo cronológico, muy digno de alabanza en consideración a su fecha, las colocó entre el paleolítico y el período precolombino tardío.

Las observaciones de Kunert se confirman por los estudios de otro explorador que estudió en el Sud del Paraguay, Mayntzhusen, quien se ocupó con gran celo y comprensión de la arqueología y etnología de estas regiones; ante el Congreso Internacional de los Americanistas dió dos conferencias sobre hallazgos de hachas de mano, descubiertas en condiciones notables $^{53}$. En su propia colonia, Mayntzhusen desenterró doce objetos líticos de trabajo tan rudimentario que apenas fué percibida su calidad de artefactos. Las ilustraciones poco claras de su relato permiten reconocer que estos instrumentos tuvieron el carácter de picks más o menos planoconvexos. Salieron de las partes más altas de un estrato pardo-rojizo de $20 \mathrm{~m}$. de espesor, bajo una capa vegetal de 30 a $40 \mathrm{~cm}$. de profundidad.

53. Manntzeusen, F. C.: Instrumpentos paleolíticos del Peraguay, en "XX Congr. intern. American." (Río de Janeiro, 1922), t. II/2, 1928, p. 117; del mismo autor: Funde altsteinzeittlicher Wentreuge im Alto Porond-Gebiet, en "XXIII Congr. intern. American". (Nueva York, 1928), 1930, p. 346. 
Aunque el terreno no fué estudiado en modo satisfactorio desde el punto de vista geológico, parece claro que la capa que contiene los artefactos debe ser de considerable edad; corresponde a un clima árido, antecedente -1 alimahámedevartual_onę nermitió.el crecimiento de la selva.

La región carece totalmente de piedras. De las cercanías de Encarnación procede una pequeña hacha de mano del tipo acheulense, por desgracia sin indicación estratigráfica. Además Mayntzhusen pudo hacer observaciones muy valiosas en el valle del Alto Paraná, entre la colonia de Hohenau (Paraguay) y las cascadas de Guaira (Brasil). Aquí yacen encima de la roca volcánica una capa delgada de arcilla gris y sobre ésa unos $20 \mathrm{~m}$. de loess pulverulento, de color ladrillo y sin piedras, cubiertos por una capa superficial parda de $30-40 \mathrm{~cm}$. En esta región, al Sud de la embocadura del arroyo Yaguarazapá, a unos 300-400 metros de distancia del Paraná, Mayntzhusen encontró hachas de mano en medio de la floresta virgen y a una profundidad de $40 \mathrm{~cm}$. Esta ubicación permite de nuevo la suposición de un yacimiento muy antiguo, como el de la colonia de Mayntzhusen. Es gran perjuicio para la ciencia que al parecer nadie apreció las comunicaciones del meritísimo explorador, ni vió la necesidad de estudiar detenidamente este asunto ${ }^{54}$. Pero tienen gran valor, aun sin averiguaciones más detenidas, porque comprueban en todo caso la existencia de un puro horizonte del hacha de mano, al menos epimiolítico, sobre las orillas del Alto Paraná. Se extendió también a la costa argentina del río, como lo indica el hallazgo de un hacha de mano en Puerto Rico, Territorio de Misiones. Fué excavada en ocasión de efectuar unas construcciones, a una profundiłạd de $25-50 \mathrm{~cm}$., en limo loessico sin piedras ${ }^{55}$.

Es probable que irradiaciones de este horizonte cultural alcanzaron el Bonaerense, y posiblemente llegaron hasta la Patagonia y Chile. Con respecto a los descubrimientos en la Provincia de Buenos Aires, merece atención el hecho que también Ameghino halló un hacha de mano en una capa intermediaria entre la tierra vegetal y el Pampeano superior ${ }^{55 a}$. En la barranca del arroyo que cruza Tandil, se encontraron instrumentos amigda-

54. Por desgracia no pude entablar relaciones con Maystzenoszs. Su enfermedad, que le ocasionó la muerte a principios del año 1949, le impidió sin duda contestar mi carta. El Director del Museo Regional de Misiones, en Posadas, señor Julio C. Sánchez Ratti, me informa que después de las publicaciones de Mayntzhusen se hicieron muchos nuevos descubrimientos de tales instrumentos primitivos. En su opinión se trata de un material relativamente reciente, hecho que demuestra una vez más la necesidad de aclarar esta cuestión de fondo.

55. Mayntzeuezn, F. C.: l. c., en "XXIII Congr. intern. American.", p. 350.

55a. Amronino, F.: Excursionos geológicas y Paleontológicas en la Provincia de Buenos Aires, en "Bol. de la Acad. Nac. de Ciencias de Córdoba", t. VI, 1884, p. 168; del mismo autor: Contribución al conocimionto de los mamiforos fósiles de la República Argentina, Buenos Aires, 1889, p. 56; Outre, F. F.: l. c., p. 308. 
loides, asociados con huesos de Equus rectidens y Palaeolama sp. ${ }^{\text {s5b. Infortuna- }}$ damente hasta ahora no fué examinada a fondo la región del arroyo Observación (hoy en día en la zona militar de Comodoro Rivadavia), a pesar de que después que yo lo hiciera, Obermaier volvió a insistir en una investigación formal ${ }^{56}$. Espero poder ocuparme de este asunto, y en general de la cuestión de las hachas de mano en el Sud de la República Argentina, en oportunidad de una proyectada expedición arqueológica a la Patagonia. En cuanto a Chile, las ideas de Capdeville y otros ${ }^{57}$ de que los estratos más bajos de los concheros de Taltal representan un verdadero Paleolítico del hacha de mano, se esfumaron por las investigaciones de Latcham $^{58}$ y Bird ${ }^{59}$. Pero es probable que los amontonamientos de conchas sobre las costas de la parte septentrional de Chile en su capa basal, reflejen todavía el eco de semejante complejo miolítico. Hasta la fecha sólo conocemos un artefacto pétreo de Chile, que posiblemente puede datarse en el verdadero Miolítico ${ }^{60}$. Es un hacha plana, tallada en ambas caras, de forma triangular, con filo débilmente curvado, hallada en una profundidad de 3 m.; semeja mucho a ciertos tipos epimiolíticos y protoneolíticos del Viejo Mundo.

En el Paraguay, Misiones, Río Grande del Sud y probablemente aun en un ámbito más vasto existió, pues, un horizonte del hacha de mano, que remonta al Epimiolítico, tal vez incluso al Miolítico. En relación con este hecho es de sumo interés que en una región vecina floreció otra rama del mismo complejo, caracterizada por su tendencia neolitizante. Nos referimos con ello a un grupo lítico en los estados San Paulo y Minas Geraes del Brasil meridional. El reconocimiento de esta facies lo agradecemos a las investigaciones de Serrano ${ }^{61}$, que se ocupó detenidamente de los concheros brasileños, los afamados sambaquí. Consiguió demostrar que no hay una

55b. Amrghino, F.: Contribucion, etc., p. 54; Outrs, F. F.: l. c., p. 308.

56. Obrrmarrr, H.: Ueber die Verwersbarkeit der altweltlicben Paläolithtypen für die prähistoriscbe Cbronologic auf amerikeniscbem Boden, en "Wiener Präh. Zeitschr.", t. XIX, 1932.

57. Capdevilir, A.: Arqueología de Taltal, en "Bol. de la Acad. Nac. de Historia", t. II/3-,5 Quito, 1921. - UnLE, M.: Sobre la estación paleolítica de Taltal, en "Publ. del Museo de etn. y antr. de Chile", t. I, 1916. - Oyarzún, A.: Estación paleolítica de Talsal, Ibídem.

58. Latcham, R. E.: Fases de la edad de piedra en Cbile, en "XXVII Congr. intern. American." (Lima, 1939), t. I, 1940.

59. Brrd, J. B.: Extavations in Nortbern Cbile, en "Anthrop. Papers of the American Mus. of Nat. Hist.", t. XXXVIII/4, 1943; del mismo autor: The Culture Sequence of the North Cbilean Coast, en J. H. Strward: Handbook of Soutb American Indians, t. II (Smithson Inst. Bureau of American Ethnology, Bull. 143), Wáshington, 1946.

60. Mednns, J. T.: Los aborígenes de Cbile, Santiago de Chile, 1882, p. 415, fig. 17.

61. Serrano, A.: Los sombaqu's o concberos brasileños, en "Rev. del Inst. de antropología de la Univers. Nac. de Tucumán", t. I/3, Tucumán, 1938; del mismo autor: La cultura lítica del Sur Brasileño, en "Rev. Geogr. Argent.", t. X, 1938; del mismo autor: Los sambaquís y atros ensayos de arqueologí brasileña, en "Anais de III Congreso sul-riograndense de bistoria e geografia", Porto Alegre, 1940. 

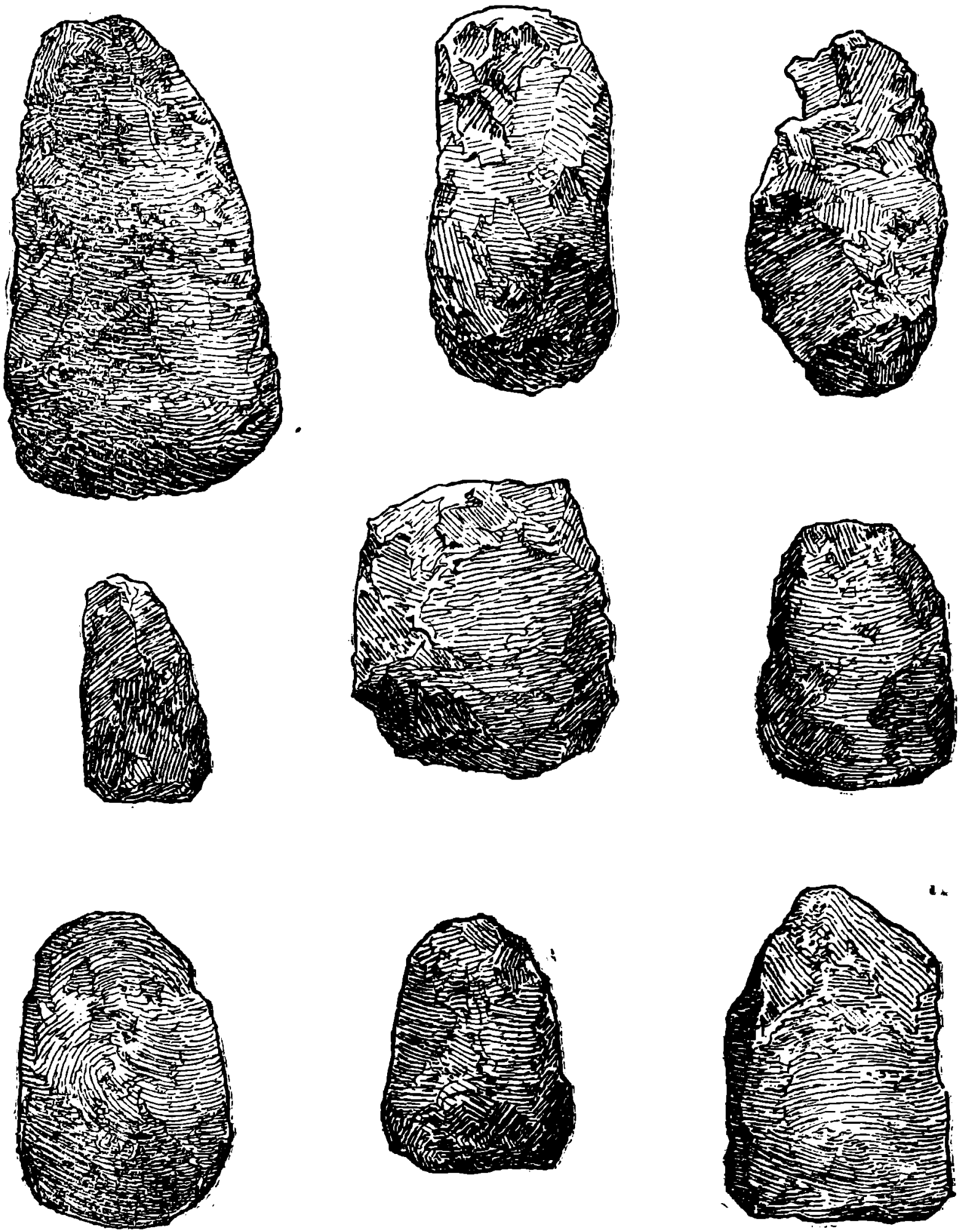

F10. 3. - Tipos de los concheros arcaicos de Igaapt, Santo Amaro y Cubatao (San Paulo, Brasil), según Serrano. Las piezas miden algo más que 2/1.

"cultura de sambaqui", sino que los concheros de Brasil se reparten en cuatro culturas distintas. Tres de ellas son relativamente modernas, y no nos interesan aquí. La otra, sin embargo, muestra carácter arcaico. En el litoral paulista - dice Serrano- es dado constatar, en sus sambaquí más 
alejados de la costa, una cultura mucho más rudimentaria que la que aparece en los más cercanos... No aparecen en esta facies las bellas hachas pulidas y las exquisitas representaciones zoomórficas de piedra... El material lítico está representado especialmente por hachas de formas más o menos triangulares u ovaladas, mal formatizadas a grandes golpes de percusión, a veces con un débil pulimento que no llegó a pulir toda la cara, pero siempre con un filo bien conseguido por este procedimiento. Algunos cuchillos y raspadores tallados - cantos rodados usados como percutores completan el instrumental lítico de esta facies cultural.

En el curso de las investigaciones que Serrano realizó en Brasil, pudo averiguar otro hecho de gran importancia. Halló en el valle del río das Velhas, en la región central del estado de Minas Geraes, una cultura bien definida, idéntica a la de los sambaquí arcaicos. En los últimos aparecen fragmentos de rocas férricas del altiplano central, lo que indica una relación inmediata entre los dos distritos. Serrano considera muy antiguos los hallazgos del río das Velhas, sin atribuirles una edad cuaternaria, y seguramente tiene razón. Más dudosa me parece, en cambio, su aseveración de que se trate de la primera cultura de la regín y que sus portadores, la raza láguida (en el sentido de Imbelloni), fueran los primeros habitantes. El mismo Serrano menciona que Padberg encontró en la entrada de la caverna de Confins (Lapa de Monte) al lado de esqueletos humanos "un instrumental óseo representado por espátulas y puntas cortadas en bisel, conjuntamente con pitones de ciervos sin trazo de trabajo". Esta noticia interesantísima sugiere la existencia de una primitiva cultura de hueso en Minas Geraes y merece tanto más atención por cuanto Serrano supone que los cráneos de este hallazgo no corresponden a los láguidos, sino posiblemente a los fuéguidos de Imbelloni. Debemos, tal vez conjeturar que una cultura de hueso antecedió a la de las hachas con filo alisado, que podemos llamar, con Serrano, cultura de Lagoa Santa. Se insinúa, sin embargo, la existencia de un segundo precursor de la última, a şaber, la originaria cultura del hacha de mano del tipo altoparanense. La extensión septentrional de la misma seguramente no se restringió al Paraguay y San Paulo, sino que abarcó una gran porción del Brasil, que debió atravesar en su migración desde el Norte. Por desgracia son casi desconocidos los países centrales y septentrionales de Sudamérica, con respecto a la edad de la piedra; de lo contrario podríamos delinear el resto del área. En todo caso, vemos que en el Sud de Brasil existe la misma situación arqueológica que en el Viejo Mundo: una cultura más primitiva del hacha de mano fué reemplazada o cubierta por una más avanzada, enriquecida de elementos neolíticos. Se trata de un progreso técnico desde el punto de vista arqueológico, que sin 
embargo no implicó necesariamente graves consecuencias con respecto a otras ramas de la vida cultural. No es difícil reconocer la fuente de esta modificación del inventario lítico. Es la misma que produjo manifestaciones análogas en el Viejo Mundo: la cultura protoneolítica del hacha cilíndrica, cuya importancia para América fué enorme. Esta cultura es el equivalente arqueológico del complejo etnológico de los plantadores más recientes, caracterizados por una horticultura evolucionada, matriarcado sin clases matrimoniales, caza de cabezas y cultos sangrientos, para mencionar sólo unos pocos rasgos importantes.

Por lo tanto, la identidad del desarrollo de las culturas del hacha de mano en Indochina y Sudamérica no se explica sino por el paralelismo de los efectos causados por la eficiencia de idénticos eventos, esto es, la superposición a una cultura del hacha de mano, de la del hacha cilíndrica.

Con la visión de un horizonte mio-epimiolítico del hacha de mano en América, se relacionan clarificaciones y problemas muy interesantes, de los que nos ocuparemos con la mayor brevedad al final de este estudio. Aprovechando las distinciones raciales efectuadas por Imbelloni ${ }^{62}$, demostró Serrano en los artículos citados la vinculación de la raza láguida con la cultura de Lagoa Santa, resultado muy importante, porque implica

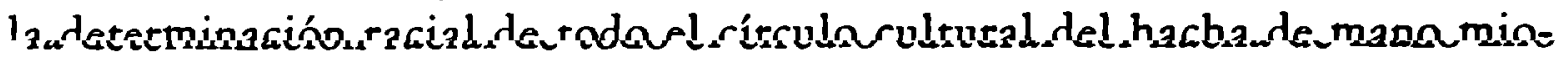
lítico en América. Dicha coherencia está comprobada por ciertos hallazgos de Minas Geraes y en los concheros arcaicos, mientras que en los sambaquí más recientes desempeña un gran papel la raza fuéguida. Eso no es extraño, a pesar de que los fuéguidos formaron seguramente una capa más antigua. Debemos presumir que se realizaron desde temprano amplios procesos de mestizaje entre los fuéguidos y los láguidos (y quizás aun con otras razas), produciendo aquella apariencia de tumultuosas sobre y yuxtaposiciones que destaca Imbelloni ${ }^{63}$. Varios descubrimientos argentinos sugieren la inmigración de los láguidos durante o hacia el fin de la última glaciación. Se sabe que Hrdlička intentó quitarle valor a todos los hallazgos americanos del hombre fósil ${ }^{64}$. Pero la ciencia moderna se alejó de su método hipercrítico. Aplicado al material europeo, su argumentación sofística descar-

62. Imbelloni, J.: Fuéguidos y Láguidos, posición actual de la raza paleoamericana o de Lagoa Santa, en "Anales del Museo Argentino de Ciencias Naturales", t. XXXIX, 1937; del mismo autor: Tres capitulos sobre sistemática del bombre americano, en "Actualidad Médica Peruana", t. II, 1937; del mismo autor: Tabla clasificatoria de los indios, en "Physis", t. XII, Buenos Aires, 1938; The Peopling of America, en "Acta Americana", t. I, 1943; del mismo autor: Sobre los dolicocéfalos del Perí antiguo, reapertura y modernización de una discusión secular, en "Homenaje a don Luis de Hoyos Sainz", tomo I, Madrid 1949, pp. 183-193. - Demвo, A.: La población indígena americana y sus grupos morfologicos, en "Revista Geográfica Americana", t. XX, 1943.

63. Imbelloni, J.: Antigüedad del hombre en América, estado actual de la cuestión, en "Ciencia e Investigación", t. III, Buenos Aires, 1947.

64. Opermaier, H.: El bombre fósil, 2a. ed., Madrid, 1925, p. 337. 
taría los más afamados esqueletos miolíticos, entre ellos los de Cromagnon. La raza láguida sobrevive hasta ahora en masa más o menos compacta precisamente en el altiplano oriental de Brasil y ocupaba, aun en tiempos relativamente modernos, toda la región entre el río Paraná y el Atlántico ${ }^{65}$. Arqueológicamente la conocemos -además- en los concheros de la parte septentrional de Chile. También se encuentra en Méjico, en la Baja California y el Sudoeste de los Estados Unidos, donde parece enlazada con las primeras etapas de la cultura de Anazasi, los 'Basket Makers'66. Probablemente también es la raza de la cultura de Cochise y sus afines.

Ya es antigua la opinión que la raza láguida está emparentada en lo básico con los Melanesios, raza negroide de Oceanía. Hrdlicka luchó reciamente contra esta teoría, contradictoria a todas sus ideas sobre la historia racial de América. Consagró a este problema un trabajo especial ${ }^{67}$, muy útil porque recapitula el desenvolvimiento de los estudios respectivos. Pero también en esta cuestión su punto de vista no logrará mantenerse. Aumentan sin cesar los adversarios de su manera de interpretar los hechos, que todos afirman las relaciones genéticas entre los láguidos y los melanesios, si bien sus proposiciones se apartan en detalles ${ }^{68}$. Esta teoría gana naturalmente por el testimonio arqueológico, el que nos enseña que ambas razas poseían un patrimonio cultural íntimamente emparentado, derivado de la cultura del hacha de mano. Este paralelismo de raza y cultura, en el caso presente se vuelve fuertemente contra otra idea, de analogía debida a desarrollo convergente, lanzada por Gates, el cual intenta interpretar casi toda semejanza morfológica entre las razas de distintos continentes

65. Imbelloni, J.: l. c. - Canats Frau, S.: Paleoemeticanos (Láguidos) en lo Mesopotamia Argentina, en "Anal. del Inst. de Etnogr. Americana de la Univ. Nac. de Cuyo", t. I, 1940.

66. Woodedry, G.: Prebistoric Skeletal Remains from Texas Coast, Gila Pueblo, Globe (Arizona), 1935, p. 41. - SAURR, C. O.: A Geographic Sketcb of Early Man in America, en "The Geographical Review", t. XXXIV, 1944.

67. Hrdučxa, A.: Melonesians and Australians and the Peopling of America, en "Smithson Misc. Coll. 94/11, Wáshington, 1935.

68. Así, por ejemplo, Imbrlloni en sus obras citadas; Buxron, L. H. D.: The "Australoid" and "Negroid" Races, en "Anthropos", t. XXX, 1935; Gladwin, H. S.: Excavations in Snaketown, t. II, Gila Pueblo, Globe (Ârizona), 1937; BAstos DE AvilA, J.: 0 bomem da Lagoa Santa, en "Cultura Médica", t. II/1, 1939; CounT, E. W.: The "Australoid" in California, en "Zeitschr. f. Rassenkunde", t. VIII, 1937; del mismo autor: Primitive Amerinds and the Australo-Melanesians, en "Rev. del Inst. de Antrop. de Tucumán", t. I/4, Tucumán, 1939; del mismo autor: The Australoid Problem and tbe Peopling of America, Ibidem, t. I/7, 1941. - RrNaUd, E. B.: Westem and Sontbwestern Indian Skulls, en "Univ. of Denver, Anthrop. Ser. I", 1941.-RIvBT, P.: Los origenes del bombre americano, México, 1943; Rivar defiende con fervor las relaciones americanooceánicas; sus argumentaciones, sin embargo, sufren de muchas debilidades. No distingue con bastance exactitud las diferentes razas y capas culturales de Oceanía ni la diversidad de sus irradiaciones hacia $\Lambda$ mérica. Cuenta con la posibilidad de relaciones transpacíficas en épocas demasiado remotas y con unz migración transártica, que es insostenible. Sus comparaciones lingǘsticas hacen desconfiar en gran medida. A pesar de todo, acierta en lo esencial. 
por la fórmula mágica de una evolución paralela ${ }^{69}$. Niega, por consecuencia, un nexo directo entre los tipos melanesio y láguido, prefiriendo explicar sus correspondencias por la derivación común del pitecántropo ${ }^{70}$. Añado que, a mi parecer ${ }^{71}$, también la raza de Brünn o Brüx, en Checoslovaquia, exhibe rasgos melanesoides. Como ya he indicado, la facies arqueológica vinculada con ella, el Predmostiense (y Protosolutrense), tiene estrechas relaciones con la cultura del hacha de mano. Por lo tanto tampoco en este caso pensaría en una convergencia en la evolución física, sino en una coherencia directa, histórica, de los grupos raciales.

Los escépticos recordarán la gran distancia que separa Indochina y el Sud de los Estados Unidos, donde se encuentran los dos centros más cercanos de estos complejos circumpacíficos. No olvidemos, sin embargo, que en el espacio intermedio se trata de regiones casi inexplotadas. ¿Quién hubiera pensado hace pocos años que aparecerían puntas Folsom en Alaska? Por ser a menudo toscos los artefactos de las culturas del hacha de mano, es mucho más difícil reconocer éstos, que los productos tan perfectos de las facies folsomoides, o sea solutroides. No olvidemos, tampoco, que se descubrieron en las partes septentrionales de los Estados Unidos muchos yacimientos con instrumentos que pueden clasificarse tipológicamente hachas de mano. Desde el punto de vista geológico, no es posible establecer la época de su origen. Pero el veredicto en absoluto negativo con respecto a una data paleolítica de todos estos objetos -como lo dió Holmes, a menudo con argumentos muy flojos - ya no es sostenible hoy en día, después de los grandes descubrimientos de culturas miolíticas en América del Norte. Parece necesario revisar varios yacimientos descartados del Paleolítico por Holmes, p. ej. Little Falls, Minnesota ${ }^{72}$. Recordamos también los materiales acarreados por Renaud en la publicación ya citada. Por lo demás, posiblemente en la bibliografía, inaccesible para mí, se hallarán tal vez muchas cosas de interés para las presentes consideraciones. Con respecto al Asia, el hallazgo de un esqueleto del tipo melanesoide en la cueva supetior de Chukutien ${ }^{73}$, que reduce considerablemente el camino al área de los láguidos, es un hecho de gran importancia.

Por lo que advierto, todos los especialistas norteamericanos están convencidos que ambos grupos mio-epimiolíticos del continente constituyen

69. Gatrs, R. R.: Human Ancestry from a Genetical Point of View, Cambridge (Mass.), 1948.

70. GATHS, R. R.: l. c., Pp. 302, 312.

71. Menouin, O.: Welsgeschicbte der Steinzeit, Viena, 1931, p. 583.

72. Ногме6, W. H.: Handbook l. c., p. 84.

73. Weidenamich, F.: On the Earliest Representatives of Modern Mankind Recovored on the Soil of East Asia, en "Nat. Hist. Bull. Peking", t. XIII, 1939; del mismo autor: Simios, Gigantes y Hembros, Buenos Aires, 1939, p. 113 (traducción castellana de la edición americana de 1946). 
el sedimento de culturas de cazadores; no piensan en la posibilidad de que uno de ellos posea carácter agrícola -ése, desde luego, debería ser el complejo de las hachas de mano, metates y útiles semejantes. Tienen la vista fija en un cuadro de desenvolvimiento conforme a la hipótesis de un único tronco cultural, que se desarrollara posteriormente en dos ramas distintas, cuya divergencia se produjera a causa de distintas condiciones ambientales, particularmente en el tiempo postglacial, cuyo clima más o menos árido originó penuria de caza en las regiones meridionales de Norteamérica y en América central. Estas circunstancias habrían obligado a los cazadores a transformarse en recolectores de plantas $y$ animales pequeños, $y$ finalmente en plantadores. Esta concepción, desde luego, es íntimamente relacionada con el quasi-dogma científico que domina los círculos de los antropólogos de Norteamérica, a saber, la doctrina que afirma que el cultivo es una invención autóctona de América.

Esta afirmación es discutible. Si fuera exacta la teoría de un origen común de los grupos miolíticos americanos, deberían observarse relaciones tipológicas mucho más claras entre sus más antiguas ramificaciones. Facies como la de Sulphur Spring o de Abilene tendrían que mostrar todavía una fuerte semejanza con las culturas folsomoides. Pero no es así. Los dos grupos más bien parecen haberse acercado sólo durante el curso de su desarrollo posterior. Según sabemos hoy, los grupos folsomoides y cochisoides son originalmente tan distintos, que no puede suponerse un origen común. Es necesario, por ende, pensar en dos invasiones. Gladwin ya lanzó esta teoría en su trabajo citado, al que sólo conozco indirectamente (por el eruditísimo libro de Martínez del Río). Por esta razón no puedo averiguar, de qué modo Gladwin vincula su complejo 'meridional' con los australoides y el complejo 'septentrional' con los melanesoides. Sin querer referirme a la extensión de los primeros, debo establecer que, según advierto, el foco de los melanesoides se encuentra en el Sud de América del Norte. El estado de las investigaciones estratigráficas actualmente no nos permite asegurar cuál de los complejos arqueológicos es más antiguo: el folsomoide o el cochisoide. Peró eso tiene poca importancia. Ya que, en el caso que el complejo cochisoide fuese el posterior, pudo abrirse paso y alcanzar regiones más deseables. Si digo más deseables, aludo al susodicho quasidogma de la prehistoria americana, la creencia del autoctonismo del cultivo en este continente. No la puedo compartir. Observemos cómo la motiva Martínez del Río" : "Ya que... la agricultura nunca fué practicada en las inmensas regiones del noroeste de Asia y del noroeste de América,

74. Martíntez der Río: l. c., p. 260. 
el hecho de suponer que los que la introdujeron hubieron de entrar por el Estrecho de Behring, nos obliga a aceptar una de dos soluciones: la primera es la de que fué traída a América por un grupo, el cual, todo dentro del corto plazo de una vida, conoció los cultivos practicados en el Asia central u oriental, se dirigió hacia el Estrecho de Behring, cruzó éste y, atravesando Alaska y el Canadá, llegó a los Estados Unidos o más abajo todavía y una vez ahí, deseoso de rehacer sus antiguos medios de existencia, empezó pacientemente a cultivar el maíz. La segunda solución es la de que tuvieron que sucederse varias generaciones de inmigrantes para llevar a cabo el viaje desde el Asia central hasta los Estados Unidos, pero que cada una de ellas explicó cuidadosamente a la siguiente la técnica de los cultivos con la recomendación de que ésta, a su vez, transmitiese lo escuchado a sus sucesores. Ambas soluciones resultan igualmente absurdas y pueden por tanto descartarse".

Parece muy persuasivo. No obstante, debo hacer algunas objeciones. El distinguido autor cuenta demasiado con la prioridad del cultivo del maíz. En América existieron probablemente culturas de plantadores muy antiguas, que no conocían el maíz. En Huaca Prieta, en el Norte de Perú, desenterró Bird ${ }^{75}$ una cultura precerámica, en la que se cultivó una media docena de plantas (algodón, calabaza, pimienta, ají, dos variedades de 'frijoles de guava', 'lenteja bocono', judía). El nivel civilizador de esta cultura alcanza una altura asombrosa, pero con excepción del instrumental lítico. Este tiene un carácter muy rudo, que sorprendió mucho al excavador, pero se adecúa muy bien a mis ideas. Según se lo puede juzgar en base a la descripción y las figuras, algo pobres, de la publicación de Bird, se trata de útiles de aspecto puramente paleolítico y harto similares a los instrumentos cochisoides, pero enriquecidos por diversos tipos sonfeccionados sobre lascas. Es precisamente el inventario pétreo, que puede esperarse en una facies que se enraíza en la cultura del hacha de mano, pero experimentó una cierta decadencia de la propia técnica lítica causada por influjos extranjeros. Bird estima el comienzo de Huaca Prieta en 2.000-3.000 a. de C. El estado de su agricultura presupone un largo tiempo de desarrollo, que necesitó al menos unos milenios, es decir una buena parte del Epimiolítico. Todo esto no parece probar nada contra un origen independiente de la domesticación de plantas en América, sino por de pronto sólo la alta antigüedad de la misma. Pero recordemos que hay botánicos que sitúan la patria del algodón en Indochina, opinión muy interesante para este conjunto, por ser Indochina sin duda un foco de irradiación de la cultura del 1948.

75. BIRd, J.: Preceramic Cultures in Chicama and Virź, en "American Antiquity", t. XIII, 
hacha de mano. Y fijémonos en que la agricultura primitiva no exige experiencia técnica. No es gran cosa el cultivo primordial. Con eso abordamos un argumento fundamental de Martínez del Río. No creo que acierta en el modo de figurarse la tradición de los conocimientos agrícolas bajo condiciones simples. El dilema que formula me parece exaltado. ¿Sería en efecto, tan difícil conservar durante algún tiempo el saber de que es posible sembrar semillas y luego recolectar una cosecha? La memoria de los primitivos con respecto a costumbres es notoriamente buena, aunque no sean llevadas a la práctica. Por otra parte, no disponemos de la más mínima base para justipreciar los lapsos de tiempo exigidos por las migraciones paleolíticas. Una vez pueden haber necesitado mucho tiempo, en otra oportunidad poco. Además debemos atender los cambios climáticos en el tiempo glacial y postglacial. El mismo Martínez del Río menciona que hubo períodos que permitieron el cultivo en Alaska. Podría imaginar que tribus miolíticas o epimiolíticas recorrieron el camino desde una a otra región cultivable en el transcurso de pocas generaciones, lo que seguramente no impidió la transmisión de la idea del cultivo. Creo, pues, poder mantener mi opinión, sugerida por las correspondencias arqueológicas y raciales entre el Antiguo y Nuevo Mundo: la agricultura de América tiene sus raíces en Asia y fué transmitida por una o varias oleadas de la cultura del hacha de mano en el tiempo del Miolítico tardío. 